\title{
Maldevelopment of Visual Motion Processing in Humans Who Had Strabismus with Onset in Infancy
}

\author{
Lawrence Tychsen* $\dagger$ and Stephen G. Lisberger* \\ *Division of Neurobiology and Department of Physiology, University of California School of Medicine, San \\ Francisco, California 94143, and \$Smith-Kettlewell Institute of Visual Sciences, San Francisco, California 94115
}

Binocular experience in infancy is necessary for the normal development of the visual cortex. However, it is not known whether binocular experience also affects the processing of specific kinds of visual information such as motion. We now report deficits in visual motion processing in 7 adult humans who lacked binocularity in infancy because of strabismus.

As probes for assessing visual motion processing, we used the initiation of smooth pursuit eye movements and the judgment of target velocity independent of eye movement. Monocular viewing was essential to reveal the deficits. For horizontal pursuit, strabismic subjects showed nasal-temporal asymmetries, such that nasally directed target motion evoked more vigorous pursuit. For vertical pursuit, strabismics showed up-down asymmetries, such that upward target motion evoked more vigorous pursuit. In addition, strabismics had abnormalities in the relative effectiveness of different parts of the visual field for initiating both horizontal and vertical pursuit. Psychophysical judgements of horizontal target velocity revealed deficits analogous to those seen in horizontal pursuit. Nasally directed stimulus motion was perceived as faster than temporally directed motion, even when the 2 directions of motion were actually presented at the same speed. The magnitude of the motion processing deficits in each subject was correlated with the severity of the clinical signs of the strabismus.

Our results suggest 2 possible interpretations. Maldevelopments of visual motion processing may cause strabismus in infancy, or alternatively, strabismus in the critical period for visual development may cause a maldevelopment of visual motion processing.

Visual experience early in life plays an important role in the development of the visual cortex. For example, a misalignment of the visual axes (strabismus) in the "critical period" for visual development has permanent effects that can be seen neurophysiologically and behaviorally (for reviews, see Boothe et al., 1985; Movshon and Van Sluyters, 1981; Wiesel, 1982). Studies of visual development in animals have focused on the primary visual cortex, where strabismus causes a loss of binocularity in the responses of individual cells (Crawford and Von Noorden, 1979; Hubel and Wiesel, 1965; Van Sluyters and Levitt, 1980).

\footnotetext{
Received Oct. 3, 1985; revised Feb. 24, 1986; accepted Mar. 3, 1986.
}

We are grateful to our subjects, who contributed substantial amounts of time to make this study possible, and to Leslie Welch and Suzanne McKee who assisted with the psychophysical testing of velocity discrimination. We thank L. Stone for his comments on an earlier version of the manuscript and T. A. Pavelko for help with many aspects of the study. The research was supported by NIH Grant EY05431 (L.T.), Fight for Sight Inc. of NYC (L.T.), the National Children's Eye Care Foundation of Washington, D.C. (L.T.), a fellowship from the Alfred P. Sloan Foundation (S.G.L.), and funds from the Academic Senate and the Research Evaluation and Allocation Committees at UCSF

Correspondence should be addressed to Stephen $G$. Lisberger, Department of Physiology, 762-S, UCSF, San Francisco, CA 94143.

Copyright (c) 1986 Society for Neuroscience $0270-6474 / 86 / 092495-14 \$ 02.00 / 0$
Behaviorally, humans who had strabismus early in life have deficits in the perception of depth using binocular cues (Mohindra et al., 1985), even if surgery later in life has realigned the eyes.

Although it is divided into discrete areas, the visual cortex can be considered as 2 parallel pathways, each of which begins in the primary visual cortex and transmits information through parts of the extrastriate visual cortex. The pathways can be defined functionally as well as anatomically: One appears to be specialized for processing visual motion and the other for processing form and color (Van Essen and Maunsell, 1983). The pathway for processing visual motion starts in the primary visual cortex and includes at least the middle temporal visual area (MT), the medial superior temporal visual area (MST), the ventral intraparietal area (VIP), and the posterior parietal cortex.

Recent work has shown that smooth pursuit eye movements are driven by visual inputs from the cortical pathways for motion processing. In humans and monkeys, pursuit requires visual inputs and is initiated by the smooth motion of a small target (Fuchs, 1967; Rashbass, 1961). Lesion studies have shown that the visual areas of the cerebral cortex play an important role in pursuit (for a review, see Leigh and Zee, 1983). The role of the cortical motion pathways was demonstrated by Newsome et al. (1985), who found deficits in pursuit after small focal lesions of area MT. The deficits were evident only when the tracking target was presented in the part of the visual field whose cortical representation had been destroyed, implying that the lesion had been made in visual rather than motor pathways.

In a preliminary study, Tychsen et al. (1985) found deficits in the smooth pursuit eye movements of adult humans who had strabismus with onset in infancy. Sinusoidal target motion revealed a directional asymmetry that depended on which eye was viewing. Pursuit was normal when the target moved nasally with respect to the viewing eye, and pursuit was weak when the target moved temporally with respect to the viewing eye. Several features of the deficit suggested to us a maldevelopment of visual rather than motor pathways. The movements of the 2 eyes were always conjugate; the direction of the deficit reversed immediately when the viewing eye was changed; smooth eye movements evoked by head rotation in the dark were normal; and subjects who acquired strabismus after the age of 2 did not show the deficit.

The abnormalities in pursuit eye movements of strabismic subjects suggested that these subjects had abnormal motion processing, since the cortical motion pathways provide the visual inputs for pursuit eye movements. One goal of our study was to use both pursuit eye movements and velocity perception to test this possibility. By using methods that provide direct estimates of the state of cortical motion processing (Lisberger and Westbrook, 1985; McKce and Welch, 1985; Tychsen and Lisberger, 1986), we have been able to verify that motion processing is abnormal in strabismic humans. We have also been able to 
Table 1. Summary of clinical status of strabismic subjects who participated in the study

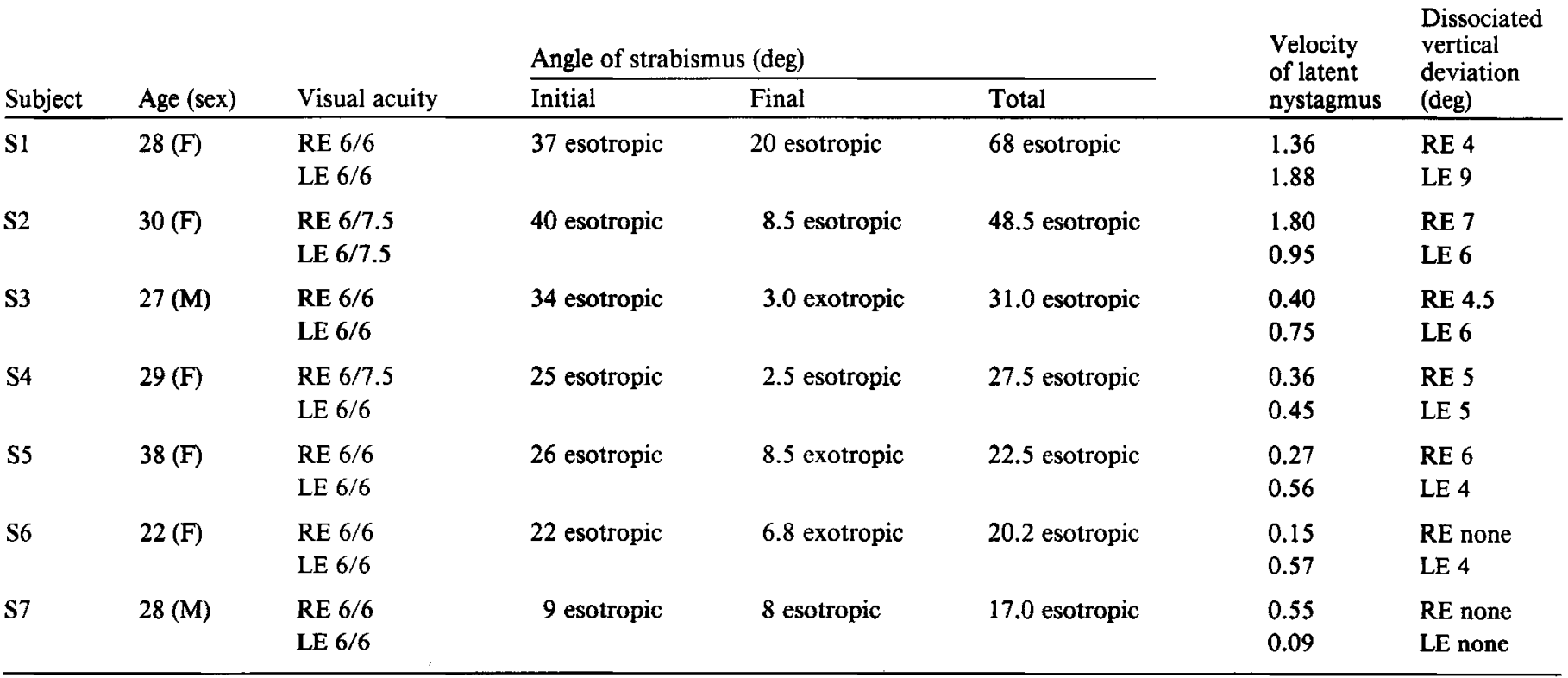

provide a quantitative description of the abnormalities.

Since all the strabismic subjects we examined had abnormalities in motion processing, the question arises of possible cause-and-effect relationships between ocular alignment and motion processing. Is correct ocular alignment necessary for the development of normal cortical motion processing? Or might abnormal motion processing cause or facilitate the acquisition of strabismus? Though our data do not resolve this issue, they reveal abnormalities in motion processing that could have contributed to the development of infantile strabismus.

\section{Materlals and Methods}

We used 2 methods to study visual motion processing in adult humans who had onset of strabismus in the first year of life (infantile or "congenital" strabismus). In 7 subjects, we measured the initiation of smooth pursuit eye movements in response to step changes in the velocity of a small target. In the 2 subjects who had the most profound deficits in pursuit, we also studied velocity perception using the psychophysical methods of McKee and Welch (1985).

\section{Subjects}

Two men and 5 women, ranging in age from 22 to 38 years old, participated as naive paid subjects. We corroborated the onset of esotropic strabismus (eyes pointing nasally) in infancy from retrieved clinical records and from facial photographs taken in the first year of life. Each subject had the constellation of ocular motor signs (Table 1) that characterize strabismus with onset in infancy (Lang, 1984) and had undergone surgery to reduce the magnitude of the strabismus before age 3 . The visual axes in all subjects remained horizontally misaligned, although to a degree that was often cosmetically inapparent. The misalignment was uniform in right and left gaze (concomitant strabismus). Six of the 7 subjects also had a dissociated vertical deviation of one or both eyes. With monocular viewing, the nonviewing eye drifted slowly upwards by as much as $9^{\circ}$. In addition, the subjects had a "latent" fixation nystagmus. Neurological development was otherwise normal.

We estimated the total angle of strabismus as the sum of the angle before the first surgery, the angle before any subsequent surgeries, and the current angle. The calculation assumes that each surgery accomplished perfect realignment of the eyes and that any subsequent deviation of the eyes represents additionally generated strabismus. The angles before surgeries were taken from clinical records, and the current angle was measured using the prism-cover test (Von Noorden, 1980) while the subject fixated an accommodative target at $6 \mathrm{~m}$. Subjects S1, S5, and S6 had more than one surgery, so that their total angles in Table 1 exceed the sum of the initial and current angles.

We specifically selected subjects who did not exhibit amblyopia in either eye. Minimum visual acuity was $6 / 7.5$ in both eyes, as measured using Snellen optotype letters. Subjects were refracted and wore corrective lenses if necessary. Four of the subjects alternated fixation; 3 preferred one eye. None of the subjects had stereopsis using the Titmus Stereo test (threshold $3000 \mathrm{sec}$ of arc) (Von Noorden, 1980).

\section{Eye movement recording}

We used a magnetic search coil (Robinson, 1963) to monitor horizontal and vertical eye position (bandpass DC to $330 \mathrm{~Hz}$ ). After instilling a drop of anesthetic ( $0.5 \%$ proparacaine) on the conjunctiva, we applied a light-weight annulus that contained the search coil and adhered by suction to the eye (Collewijn et al., 1975). During experiments each subject sat in the center of 6-foot-diameter field coils. The head was supported on a chin rest so that the eye was $50 \mathrm{~cm}$ from a translucent tangent screen that subtended $60^{\circ} \times 60^{\circ}$ of visual angle. The eye coil was calibrated by having the subject fixate targets at known positions. Unless we state otherwise, viewing was monocular through the eye carrying the coil. In successive rccording sessions the eye carrying the coil was alternated. Visual acuity was checked at the end of experiments to ensure that the coil had not degraded visual acuity by more than one optotype line.

\section{Presentation of pursuit targets}

Two visual targets were projected onto the back of the tangent screen. One was a rectangle (6 min wide $\times 10 \mathrm{~min}$ high) that remained stationary at straight ahead gaze. The other was a circle $(6 \mathrm{~min}$ diameter) that was reflected off a pair of servocontrolled mirror galvanometers and could be moved horizontally or vertically. The room was dimly lit, and the intensity of the movable target was $2.8 \mathrm{log}$ units above our threshold for detection of a $100 \mathrm{msec}$ flash.

Most of our experiments used the strategy illustrated in Figure 1 to present the pursuit target in individual trials of ramp motion. Each trial began by illuminating the stationary rectangle at straight ahead gaze (horizontal dashed lines) and the tracking target at an eccentric position along the horizontal or vertical meridian (solid lines labeled targ pos). The subject was required to keep eye position within a $\pm 2^{\circ}$ window of the rectangle for a random interval of $500-900 \mathrm{msec}$. At an unpredictable time shown by the end of the dashed lines, the rectangle disappeared and the tracking target began simultaneously to move toward or away from the position of fixation. This approach allowed us to deliver image motion at a precise retinal location that was determined by the relative 
positions of the 2 targets. For example, the tracking target started at $6^{\circ}$ left in Figure $1 A$ and at $6^{\circ}$ right in Figure $1 B$, so that the ramp motion provided images moving towards the fovea from $6^{\circ}$ eccentric. The pursuit stimulus was equivalent to the "step-ramp" of Rashbass (1961) but avoided the high-velocity streak of light seen when mirror-galvanometers attempt to execute a step change in target position.

A typical 25 min session consisted of 300-400 trials drawn in random order from 15-20 possible combinations of initial target position (eccentricities of $0^{\circ}-15^{\circ}$ ), direction of target motion (rightward, leftward, upward, or downward), and target velocity (range, $0.5-30 \% / \mathrm{sec}$ ). A DEC $11 / 23$ computer controlled the experiments, repeating each possible combination about 20 times within a given session.

Figure 1 shows 2 trials in which ramp target motion evoked several hundred msec of smooth pursuit before the first saccadic eye movement, which did not occur until after the sections of record shown. However, some subjects had very short saccadic latencies and sometimes made saccades that coincided with the initiation of pursuit. Our data analysis required at least $75 \mathrm{msec}$ of smooth pursuit before the first saccade. To achieve this much presaccadic pursuit, we intermixed conditioning trials that lengthened saccadic latencies. Conditioning trials began in the way described above, so that the subject could not recognize a priori that they were different. At $80 \mathrm{msec}$ after the onset of ramp motion, the moving target underwent a step change in position that was adjusted to obviate the need for any saccade. The target then continued to move at the initial ramp velocity. The conditioning trials lengthened the latency for saccades without having any obvious effect on the initiation of pursuit. Conditioning trials were included in each experiment but were not analyzed.

In each subject, we tested pursuit of sinusoidal target motion at 0.4 $\mathrm{Hz}, \pm 10^{\circ}$. Fifteen cycles of pursuit were recorded, first while the subject viewed with the eye carrying the coil, and second while the coil-fitted eye was covered so that the subject viewed with the other eye. We also recorded the fixation nystagmus while the subject viewed monocularly through each eye in succession and fixated a spot at straight ahead gaze.

\section{Data acquisition and analysis}

We obtained voltages proportional to horizontal and vertical eye velocity by passing the eye position signals through analog differentiators (bandpass DC to $50 \mathrm{~Hz},-20 \mathrm{~dB} /$ decade). The resulting signals had less than $1 \% \mathrm{sec}$ of noise. The relevant eye velocity, eye position, and target position signals were digitized by the computer during each experiment and saved for later analysis. Each channel was sampled every $1 \mathrm{msec}$ for ramp tracking, and every $2 \mathrm{msec}$ for continuous tracking or fixation.

Data were analyzed using an interactive computer program. For ramp tracking, each trial was displayed on a video monitor for inspection. The trial was accepted for analysis if eye velocity was stable for 100 msec before target movement, and if at least $75 \mathrm{msec}$ of smooth eye velocity was recorded before the first saccade. Most trials provided at least $100 \mathrm{msec}$ of presaccadic pursuit, and less than $20 \%$ of trials were rejected. If a saccade was recorded after $75 \mathrm{msec}$ of pursuit, its beginning and ending points were marked with a keyboard-controlled cursor. The computer then excised the rapid deflection from the eye velocity record and connected the beginning and ending points of the missing segment with a line. The interpolated segment usually fit smoothly into the record. If it did not, the trial was discarded. Edited eye velocity records from at least 15 identical trials were then aligned on the onset of target motion and averaged. We used the averaged eye velocity records to point out the initiation of pursuit and to measure mean eye acceleration in the first $100 \mathrm{msec}$ of pursuit. For some experiments, we also averaged the values of eye acceleration measured from each individual trial. This yielded numbers that were within $10 \%$ of those obtained from averaged records and provided the values of SD that have been plotted in the figures.

Pursuit of periodic target motion was analyzed after excising saccades from the eye velocity record in the way described above. Ten consecutive cycles of eye velocity were averaged and subjected to Fourier analysis. Because monocular viewing reveals nasal-temporal asymmetries when strabismic subjects pursue sinusoidal target motion (Tychsen et al., 1985 ), the Fourier analysis yielded a DC level of eye velocity that was different from zero. We estimated the nasal-temporal asymmetry using the ratio $(A+D C) /(A-D C)$, where $A$ was the amplitude of the fundamental component of eye velocity and the DC shift was given a positive sign when it was nasally directed. The ratio would have been 1.0 if there were no asymmetry between nasally and temporally directed eye velocity, and it would have been greater than 1.0 if nasally directed
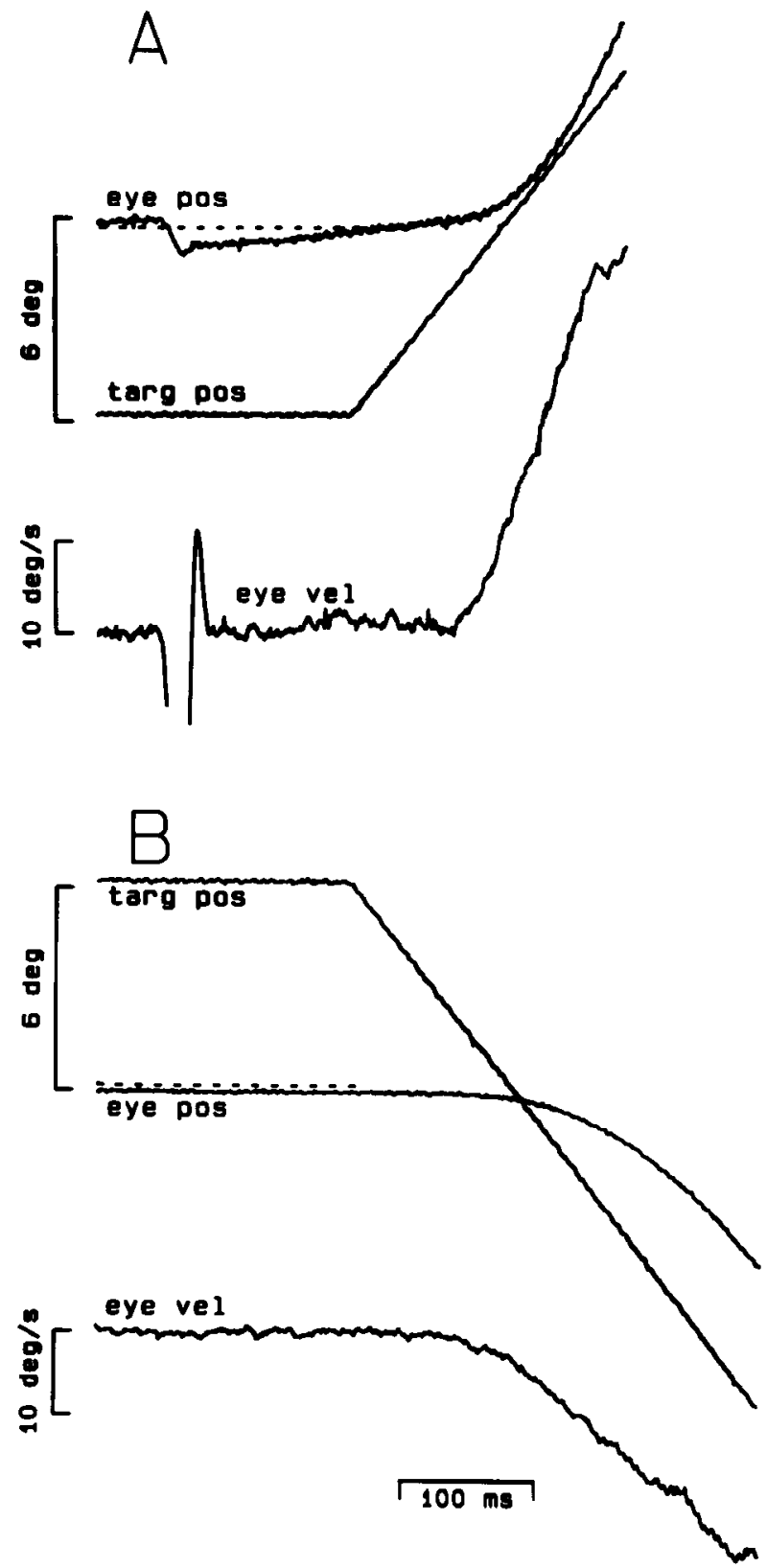

Figure 1. Representative records showing the initiation of pursuit for nasally $(A)$ and temporally $(B)$ directed target motion in a strabismic subject (S4). Viewing was with the left eye. In both panels, the target started $6^{\circ}$ eccentric and moved at $30^{\circ} / \mathrm{sec}$ toward the position of fixation. Horizontal dashed lines indicate the position of the fixation rectangle (straight-ahead gaze). At the moment when the tracking target began to move, the fixation rectangle was extinguished. Upward deflections indicate rightward positions and velocities.

eye velocity were larger. The magnitude of the fixation nystagmus was measured as the mean of the average eye velocity for each of 15 consecutive slow phases.

\section{Psychophysical measurement of velocity detection}

The method of single stimuli (McKee and Welch, 1985) was used to study foveal velocity discrimination in 2 strabismics who had also participated in the pursuit part of the study, and in 2 normal subjects. The subject sat $228 \mathrm{~cm}$ from a cathode ray tube (CRT) screen (P4 phosphor) that subtended $2^{\circ}$ vertically $\times 2.5^{\circ}$ horizontally. The target was a vertical rectangle ( $9 \mathrm{~min}$ arc by $2 \mathrm{~min}$ arc) that moved horiziontally. The contrast between the target $\left(2650 \mathrm{~cd} / \mathrm{cm}^{2}\right)$ and the background $\left(50 \mathrm{~cd} / \mathrm{cm}^{2}\right)$ was 
Figure 2. Comparison of the initiation of pursuit for horizontal target motion in a normal subject $(A)$ and a strabismic subject $(B)$. Each arrow plots average eye acceleration in the first $100 \mathrm{msec}$ of pursuit as a function of the initial position of the moving targets. Direction pointed by each arrow represents the direction of target motion. Viewing was with the left eye, so that the open arrows show responses to nasally directed target motion, and the filled arrows show responses to temporally directed target motion. Vertical dashed lines indicate the position of fixation. Negative values of target position indicate that the target started in the left visual field. Error bars show SD.
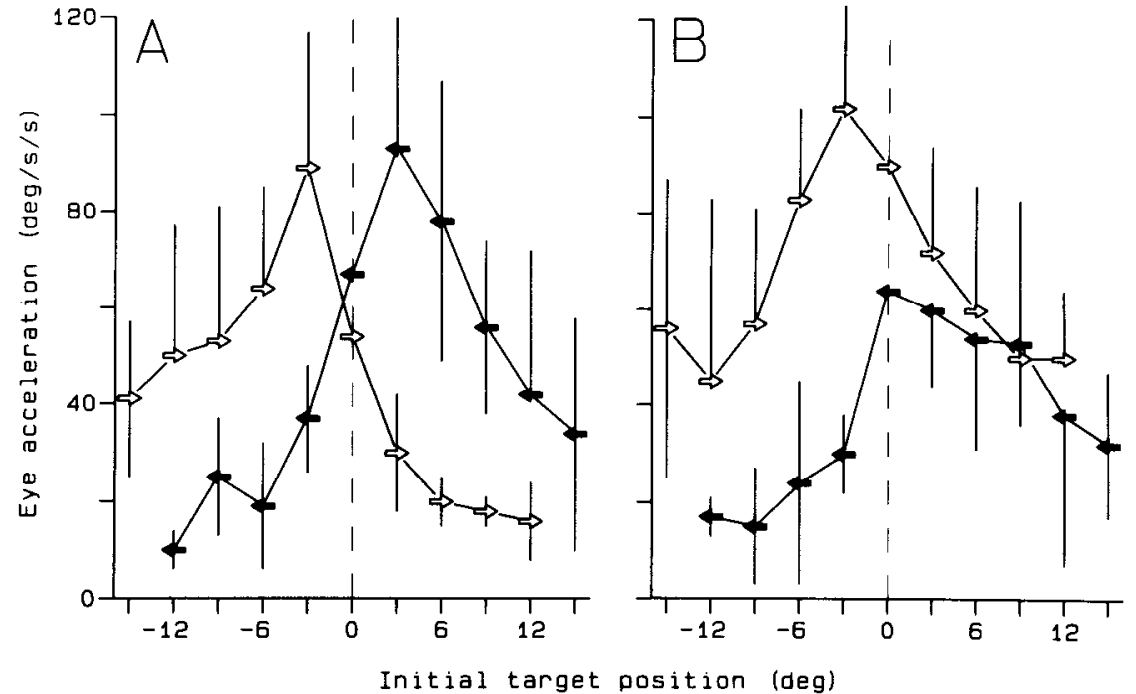

$1.7 \log$ units. The subject viewed monocularly and fixated a small black mark in the center of the CRT screen.

Experiments were conducted as a series of trials, each of which presented target motion at 1 of 5 closely spaced velocities. After each trial, the subject responded by pressing 1 of 2 buttons to indicate whether the trial was faster or slower than the perceived mean. Subjects were trained with monocular viewing by providing them with nasally directed target motion at $13.5,14.25,15,15.75$, and $16.5 \% / \mathrm{sec}$. They were able, with auditory feedback, to learn the task within 20 trials. We then withheld feedback, intermixed nasally and temporally directed motion, and delivered 300 trials in random order. To prevent the subject from using the duration of the stimulus or the length of its path across the oscilloscope to discriminate between fast and slow velocities, we also randomized the duration of the stimulus to be $100 \pm 20 \mathrm{msec}$. Each subject's responses were sorted so that we could evaluate velocity discrimination separately for nasally and temporally directed motion. For each subject, successive blocks of trials were run, first with the left eye viewing and then with the right.

\section{Results}

\section{Initiation of horizontal pursuit in normal subjects}

The deficits we have found in strabismic subjects can be appreciated only by comparision with the performance of normal adult humans in the same experimental conditions. Figure $2 \mathrm{~A}$ plots eye acceleration in the first $100 \mathrm{msec}$ of pursuit as a function of the initial position of the tracking target for viewing with the left eye in a normal subject. Two general findings can be seen. First, the magnitude of eye acceleration was nearly equal for leftward (temporally directed) and rightward (nasally directed) target motion. Second, eye acceleration was larger when the target moved toward rather than away from the position of fixation. Thus, leftward eye acceleration was largest when the target started at $3^{\circ}$ right, and rightward eye acceleration was largest when the target started at $3^{\circ}$ left. These 2 general findings

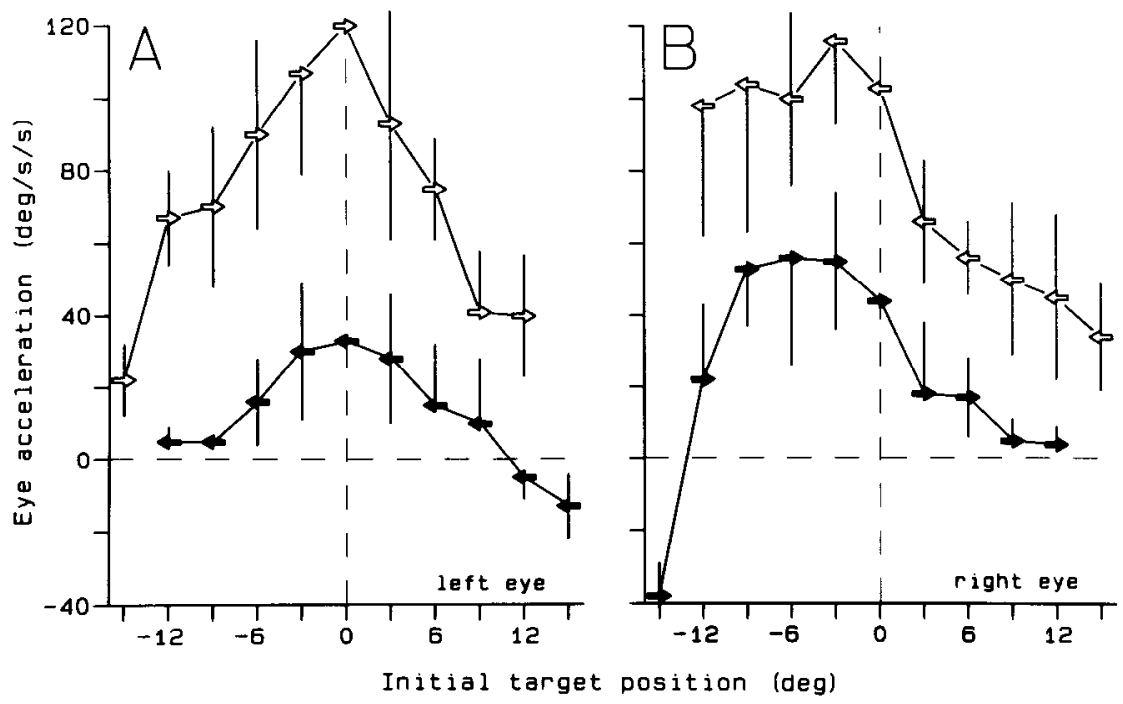

Figure 3. Nasal-temporal asymmetries for the initiation of pursuit when viewing through the left $(A)$ or right $(B)$ eye (subject $\mathrm{S} 2)$. Each arrow plots mean eye acceleration in the first $100 \mathrm{msec}$ of pursuit as a function of initial target position and direction of motion. Open symbols show the responses to nasally directed target motion, i.e., rightward when the left eye was viewing $(A)$ and leftward when the right eye was viewing $(B)$. Vertical dashed lines show the position of fixation. Positive values of eye acceleration represent pursuit in the direction of target motion, while negative values of eye acceleration (below the horizontal dashed line) indicate eye acceleration in the direction opposite to target motion. This subject consistently initiated nasally directed pursuit in response to temporally directed target motion that startcd $12^{\circ}-15^{\circ} \mathrm{ccccntric}$ and moved toward the position of fixation. Negative values of target position indicate that the target started in the left visual field. Error bars show SD. 

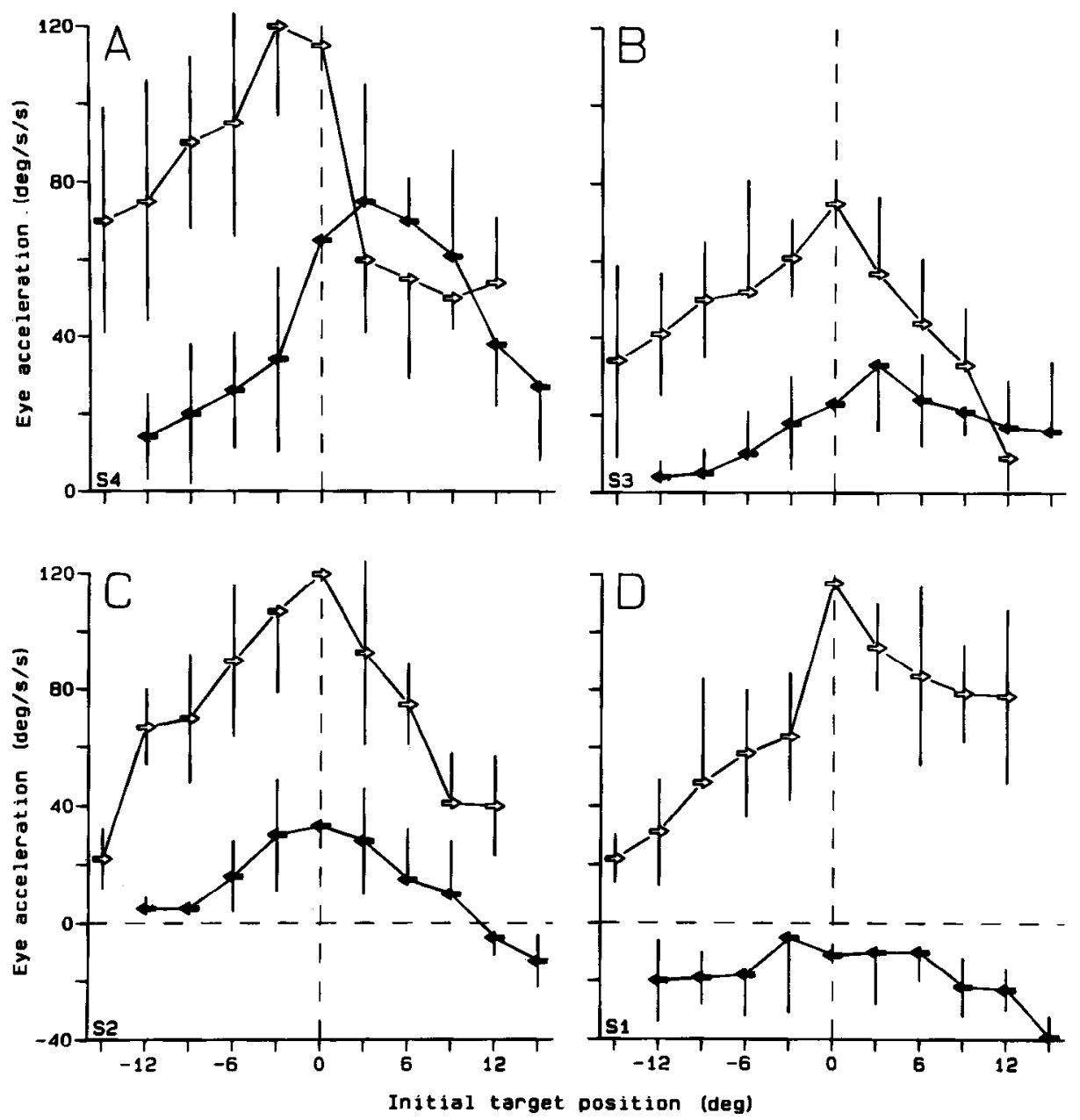

Figure 4. Range of nasal-temporal pursuit asymmetries in 4 strabismic subjects. Each panel shows data for one subject and plots mean eye acceleration in the first $100 \mathrm{msec}$ of pursuit as a function of the direction of target motion and the initial target position, For each subject, viewing was through the left eye, so that the open arrows show responses to rightward or nasally directed target motion. Vertical dashed lines show the position of fixation. The negative values of eye acceleration in subjects $\mathbf{S} 2(C)$ and $\mathbf{S} 1(D)$ (arrows plotted below the horizontal dashed lines) indicate that temporally directed target motion caused the initiation of nasally directed pursuit. Negative values of target position indicate that the target started in the left visual field. Error bars show SD.

result in the mirror-image symmetry of nasally and temporally directed target motion seen in Figure $2 A$. Similar relationships were found in another study of 6 normal subjects (Tychsen and Lisberger, 1986).

\section{Nasal-temporal asymmetries in pursuit initiation in strabismic subjects}

When viewing monocularly, strabismic subjects initiated pursuit strongly when the target moved in a nasal direction and weakly when the target moved in a temporal direction. For example, Figure 1 shows the eye movements that were evoked when the left eye viewed target motion to the right $(A)$ or left $(B)$. In both panels, the movable spot started at $6^{\circ}$ eccentric and moved at $30 \% \mathrm{sec}$ toward the position of fixation. The initiation of pursuit can be seen most clearly in the eye velocity records, which showed a brisk increase when the spot moved nasally $(A)$ and a weaker response when the spot moved temporally $(B)$.

Figure $2 B$ summarizes the initiation of pursuit for the strabismic subject of Figure 1 during viewing with the left eye. Peak rightward (nasally directed) eye acceleration was $41 \% \mathrm{sec}^{2}$ larger than peak leftward (temporally directed) eye acceleration. The consistency of the nasal-temporal asymmetry can be seen by considering responses to targets that started at analogous positions and moved in the same direction with respect to the position of fixation. For example, in Figure $2 B$ the open arrows to the left of the vertical dashed line and the filled arrows to the right of the vertical line both represent responses to target motion toward the point of fixation. Comparison reveals that nasally directed eye acceleration was higher at each initial position.
In strabismic subjects, changing the eye used for viewing the target reversed the asymmetry in terms of right and left, so that nasally directed target motion always remained more effective. Figure 3 shows the relationships between eye acceleration and initial target position for both eyes of another strabismic subject. Eye acceleration was larger for rightward pursuit when viewing through the left eye (Fig. $3 A$ ) and for leftward pursuit when viewing through the right eye (Fig. $3 B$ ). The nasal-temporal asymmetry was slightly more pronounced with the left eye viewing, but the responses for viewing through the 2 eyes were otherwise similar. In Figure 3, as in most of our experiments, we fitted the coil to the viewing eye and had no direct measure of the movements of the patched eye. In one experiment, howevcr, we measured the movements of the left eye while subject S1 viewed with the right eye. This verified that the direction of the pursuit asymmetry depended on the viewing eye.

The magnitude of the nasal-temporal asymmetry varied widely among our 7 subjects and was correlated with each subject's total angle of strabismus. Figure 4 shows the relationships between eye acceleration and initial target position for the left eyes of 4 strabismic subjects and illustrates the range we found. Figure 5 plots the total angle of strabismus as a function of the magnitude of the nasal-temporal pursuit asymmetry, defined as peak eye acceleration for nasally directed target motion minus peak eye acceleration for temporally directed target motion. Each point represents 1 eye, and the points representing the 2 eyes of each subject are connected by horiziontal lines. The pursuit asymmetry was more highly correlated with the total magnitude of the strabismus $(R=0.94,13$ eyes $)$ than with either 


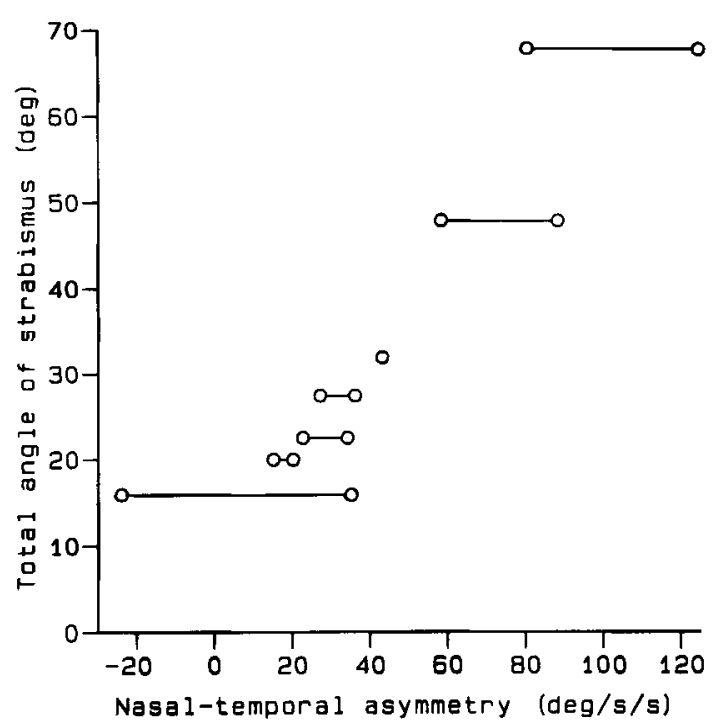

Figure 5. Relationship between pursuit asymmetry and total magnitude of strabismus. Each point represents the responses viewing through one eye. The lines connect the points representing the 2 eyes of a given subject. Positive values of nasal-lemporal asymmetry indicate that the peak nasally directed eye acceleration was larger than the peak temporally directed eye acceleration.

the initial angle of strabismus $(R=0.80)$ or the current angle of strabismus $(R=0.57)$. In Figure 5 , one eye from the subject with the smallest angle of strabismus had a negative value of pursuit asymmetry. When viewing with his left eye, acceleration was $24 \% \mathrm{sec}^{2}$ higher for temporally directed (leftward) target motion. When viewing with his right eye, acceleration was $35 \% / \mathrm{sec}^{2}$ higher for nasally directed (leftward) target motion. Thus, the asymmetry in this subject was predominantly left-right, rather than nasal-temporal, and we have not included his data in the remainder of this report.

Two subjects with particularly severe nasal-temporal asymmetries (subject S1 of Fig. $4 D$ and subject S2 of Fig. 3) often responded to temporally directed target motion by initiating nasally directed pursuit. Figure 6 shows one example of wrongway pursuit in subject $S 1$ during viewing with the left eye. The target started at $12^{\circ}$ eccentric and moved temporally (leftward) toward the position of fixation. After a latency of $105 \mathrm{msec}$ (downward arrow), the subject began to pursue smoothly in the wrong direction, to the right. The velocity record shows that the eye accelerated smoothly in the wrong direction for 120 msec before the subject made a saccade, which was in the direction of target offset. In this example, the saccade was hypermetric. We did not examine the saccades systematically, so we do not know whether the example of Figure 6 was typical.

In Figure 3, the negative values of eye acceleration indicate that subject $\mathrm{S} 2$ initiated pursuit in the wrong direction when the target started $12^{\circ}-15^{\circ}$ eccentric and underwent temporally directed motion toward the position of fixation. The wrongway pursuit was more pronounced in subject $S 1$, who initiated nasally directed pursuit for temporally directed target motion at all initial target positions (Fig. 4D). In a separate experiment not plotted on our graphs, subject $S 1$ 's wrong-way accelerations increased as a function of initial target position, up to a value of $61 \% \mathrm{sec}^{2}$, for targets that started $32^{\circ}$ eccentric in the nasal visual field and moved temporally toward the position of fixation.

\section{Abnormalities in the topography of horizontal pursuit}

Inspection of Figures $2 B, 3$, and 4 reveals a second abnormality that was evident for both nasally and temporally directed target

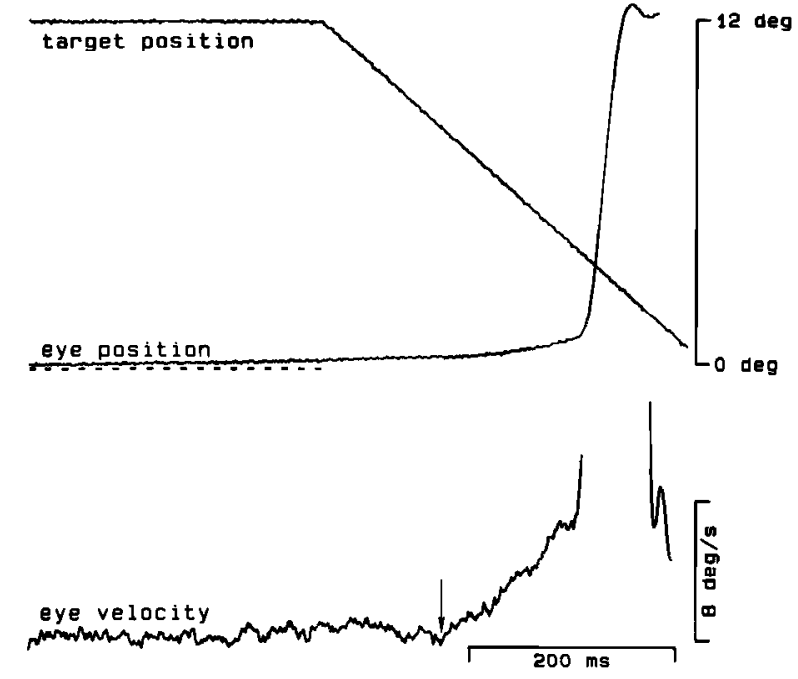

Figure 6. Example of wrong-way pursuit for temporally directed target motion in subject S1. The subject viewed with the left eye. Horizontal dashed line shows the position of the fixation rectangle of the onset of target motion. The tracking target started at $12^{\circ}$ eccentric and moved leftward (temporally) toward the position of fixation. At the time indicated by the arrow, the subject initiated rightward (nasally directed) pursuit.

motion. Strabismics showed abnormal weighting of different parts of the visual field for the initiation of pursuit. In Figure $4, B-D$, for example, nasally directed target motion (open arrows) evoked the largest eye accelerations when the target started at the position of fixation. The most abnormal weightings of the visual field occurred in the strabismic subjects with the most pronounced nasal-temporal asymmetries. For nasally directed target motion, subjects $S 1$ and $S 2$ had higher accelerations when the target moved away from the position of fixation (Figs. 3B, $4 D$ ). In contrast, normal subjects always had higher eye accelerations when the target moved toward the position of fixation (Fig. $2 A$ ). We refer to this class of abnormalities as changes in the "topography" of the pursuit response, by analogy to the retinotopic representation of the visual field on the visual cortex.

We quantified the topography of the pursuit response by computing the "topographic median" for each curve relating eye acceleration to target position. We defined topographic median as the target position that divided the area under the curve into 2 equal parts. In Figure 7, each point plots the topographic median as a function of the pursuit asymmetry for viewing through one eye. The graphs compare the topography in normal and strabismic subjects for both nasally (Fig. $7 A$ ) and temporally directed (Fig. 7B) target motion. In normal subjects (circles), the pursuit asymmetry was close to zero, and the topographic median fell at positive values, $2^{\circ}-3^{\circ}$ eccentric from the position of fixation. Thus, normal subjects show an overall preference for targets moving toward the position of fixation. In strabismic subjects (squares), eyes with small pursuit asymmetries had topographic medians close to or within the normal range, but eyes with severe pursuit asymmetries had large shifts in the topographic median. For both nasally and temporally directed target motion, the cycs with the largest asymmetries had negative values of topographic median, indicating a preference for target motion away from the position of fixation.

\section{Nasal-temporal asymmetries for sinusoidal target motion}

Our subjects, like those reportcd carlier (Tychsen et al., 1985), had a nasal-temporal asymmetry during pursuit of sinusoidal target motion with monocular viewing. In a single session, we recorded the movements of one eye, first with it and then with 


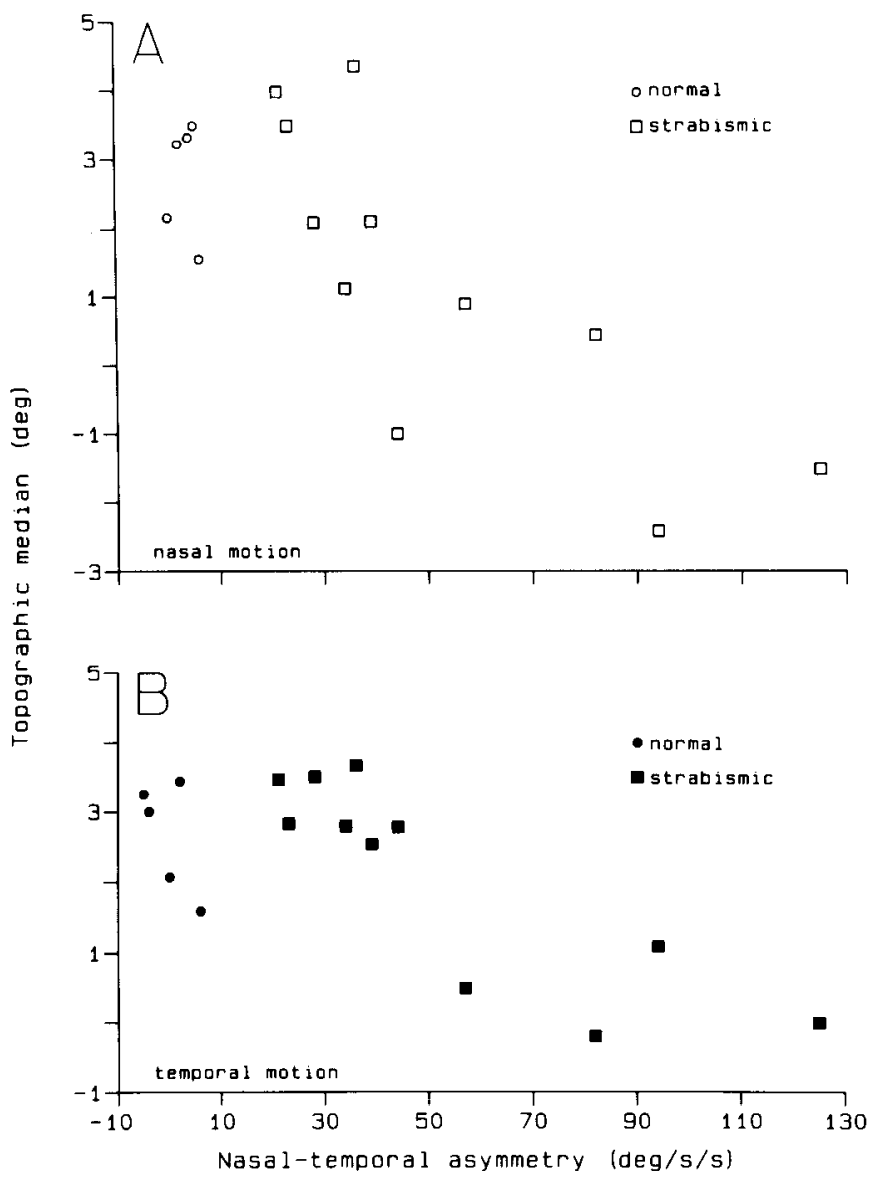

Figure 7. Abnormalities in the relative weighting of the visual field for the initiation of horizontal pursuit in strabismics. Each point represents the responses for viewing with one eye in one normal (circles) or strabismic (squares) subject. Topographic median is an estimate of the center of the curve relating eye acceleration to the initial position of the tracking target. Positive values indicate that eye acceleration was generally larger for target motion toward the position of fixation, and negative values indicate that eye acceleration favored target motion away from the position of fixation. Note that strabismics with large nasal-temporal asymmetries showed abnormalities in topographic median for both nasally $(A)$ and temporally $(B)$ directed target motion.

the other eye viewing. In successive experiments we recorded the movements of the left and then the right eyes. We were thereby able to verify that the direction of the deficit depended only on the viewing eye. During the half cycle when the target moved nasally with respect to the viewing eye, pursuit was smooth and eye velocity was nearly equal to target velocity. As the target moved temporally, pursuit was partly saccadic and eye velocity was less than target velocity. We used Fourier analysis to estimate the magnitude of the asymmetry during sinusoidal tracking (see Materials and Methods). The nasal-temporal asymmetry during sinusoidal pursuit was highly correlated with the nasal-temporal asymmetry during the initiation of pursuit for ramp target motion (Fig. $8 A, R=0.91,11$ eyes).

\section{Nasally directed drift during attempted fixation}

Each strabismic subject had a nystagmus on attempted fixation such that the slow phases were directed nasally with respect to the viewing eye. The nystagmus was conjugate, so that both eyes had rightward slow phases when the left eye was viewing. Figure $8 B$ shows that the mean velocity of the slow phase for each viewing eye was closely related to the magnitude of the nasal-temporal asymmetry for the initiation of pursuit $(R=$
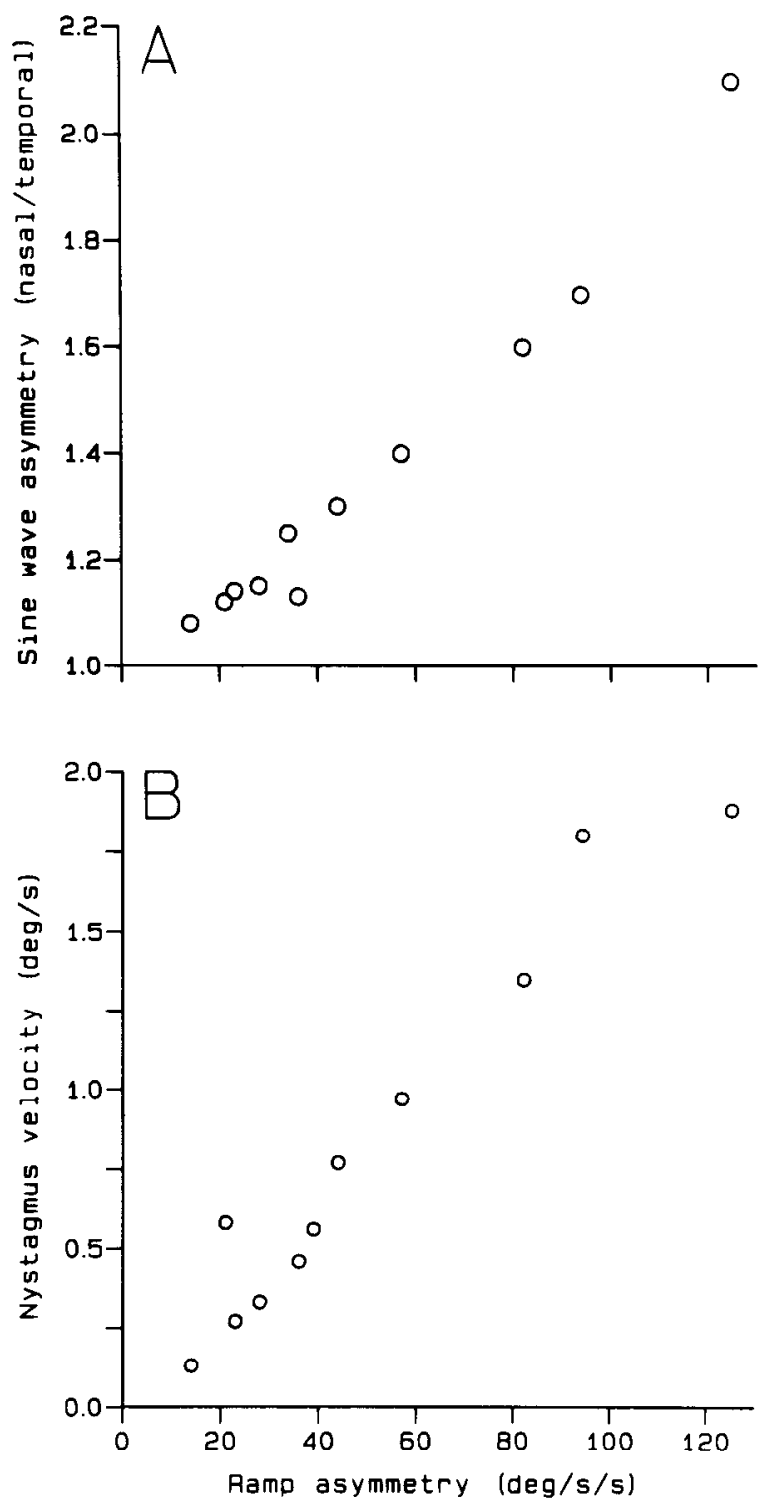

Figure 8. Comparision of asymmetry during the initiation of pursuit with deficits revealed during sine wave tracking $(A)$ or steady fixation $(B)$. Each point represents the responses for viewing through one eye in one strabismic subject. $A$, Ordinate plots the nasal-temporal asymmetry during tracking of sine wave target motion at $0.4 \mathrm{~Hz} \pm 10^{\circ} . B$, Ordinate plots the mean velocity of the slow phases of the "latent" nystagmus during fixation of a small target. In both panels, the abscissa plots the nasal-temporal asymmetry during the initiation of pursuit for ramp target motion.

$0.96,11$ eyes). The nystagmus velocities of Figure $8 B$ and Table 1 were measured from records obtained while the subject fixated the spot at straight ahead gaze, in the same visual conditions used to reveal the pursuit asymmetry.

The velocity of the nystagmus depended on the relative illumination of the spot and the background. In the 3 strabismic subjects we tested systematically, the mean slow phase velocities were $0.37,0.69$, and $1.23 \% \mathrm{sec}$ during fixation of the spot in an otherwise dark room. When the background was brightly illuminated, the mean slow phase velocity decreased, averaging $78 \%$ of that during fixation of the spot alone. In total darkness (no fixation spot), the velocity of the nystagmus decreased further and averaged $29 \%$ of that during fixation of the spot alone. 
Figure 9. Wrong-way pursuit for low-velocity target motion. $A$, Example of the response to leftward image motion at $1.0 \% \mathrm{sec}$ with the left eye viewing in subject $\mathbf{S 5}$. Beginning at the moment indicated by the $u p$ ward arrow, the target was driven with a signal composed of actual eye position plus the $1.0 \% \mathrm{sec}$ stimulus so that the small error could not be corrected. Downward arrow points out the initiation of rightward pursuit. $B$, Mean eye acceleration for nasally (open arrows) and temporally (filled arrows) directed target motion at 1.0 or $2.5 \%$ sec, plotted as a function of initial target position. Vertical dashed line shows the position of fixation. Negative values of eye acceleration (below the horizontal dashed line) indicate that the subject pursued in the direction opposite to target motion. Error bars show SD.

Wrong-way pursuit for low-velocity target motion

During fixation of a stationary target, the nasally directed slow phases of the nystagmus produced retinal image motion equivalent to that of a target moving in a temporal direction at a low
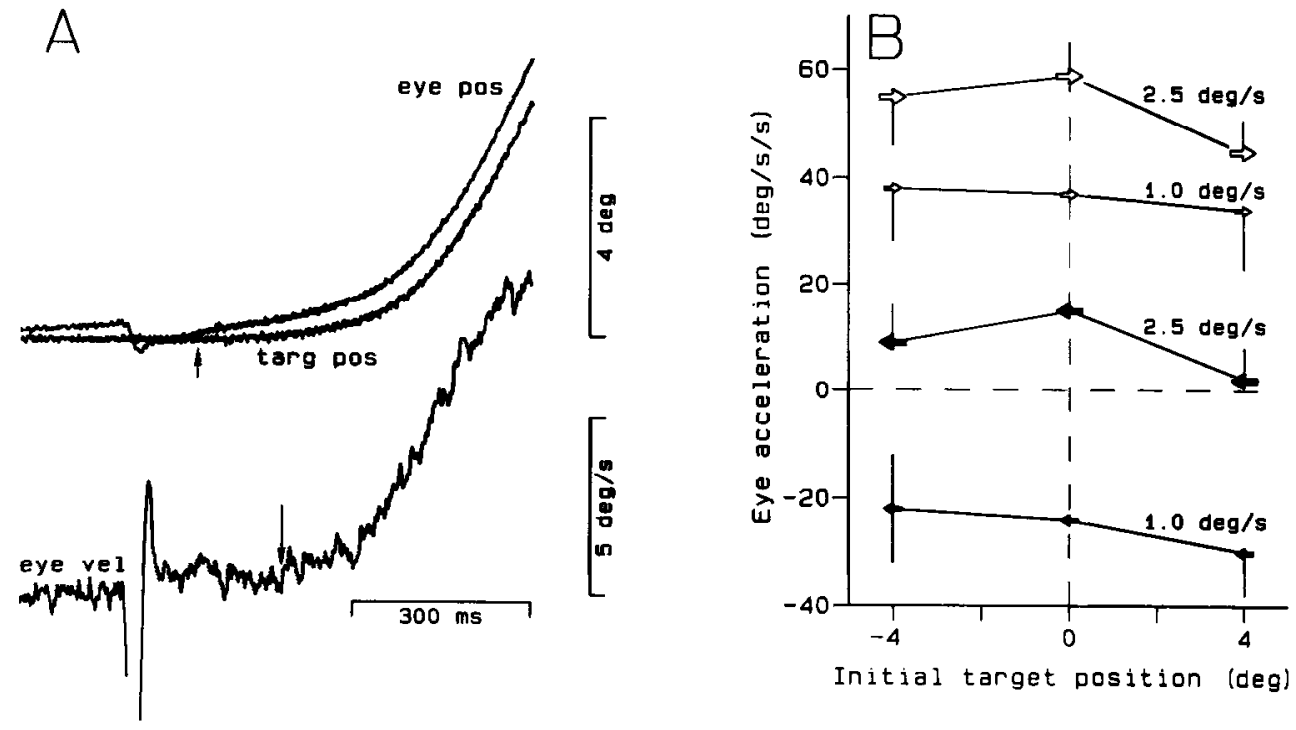

velocity. We could understand why the subject, whose data are shown in Figure $4 D$, was unable to use pursuit to overcome the nystagmus since she never initiated temporally directed pursuit. However, all the other subjects could initiate some temporally directed pursuit, and we were surprised that they did not use
Figure 10. Initiation of vertical pursuit in 1 normal $(A)$ and 3 strabismic $(B-D)$ subjects. Each arrow plots mean vertical eye acceleration as a function of the initial target position along the vertical meridian. Direction of each arrow shows the direction of target motion; vertical dashed lines indicate the position of fixation. Negative values of target position indicate that the target started in the lower visual field. Error bars show SD.
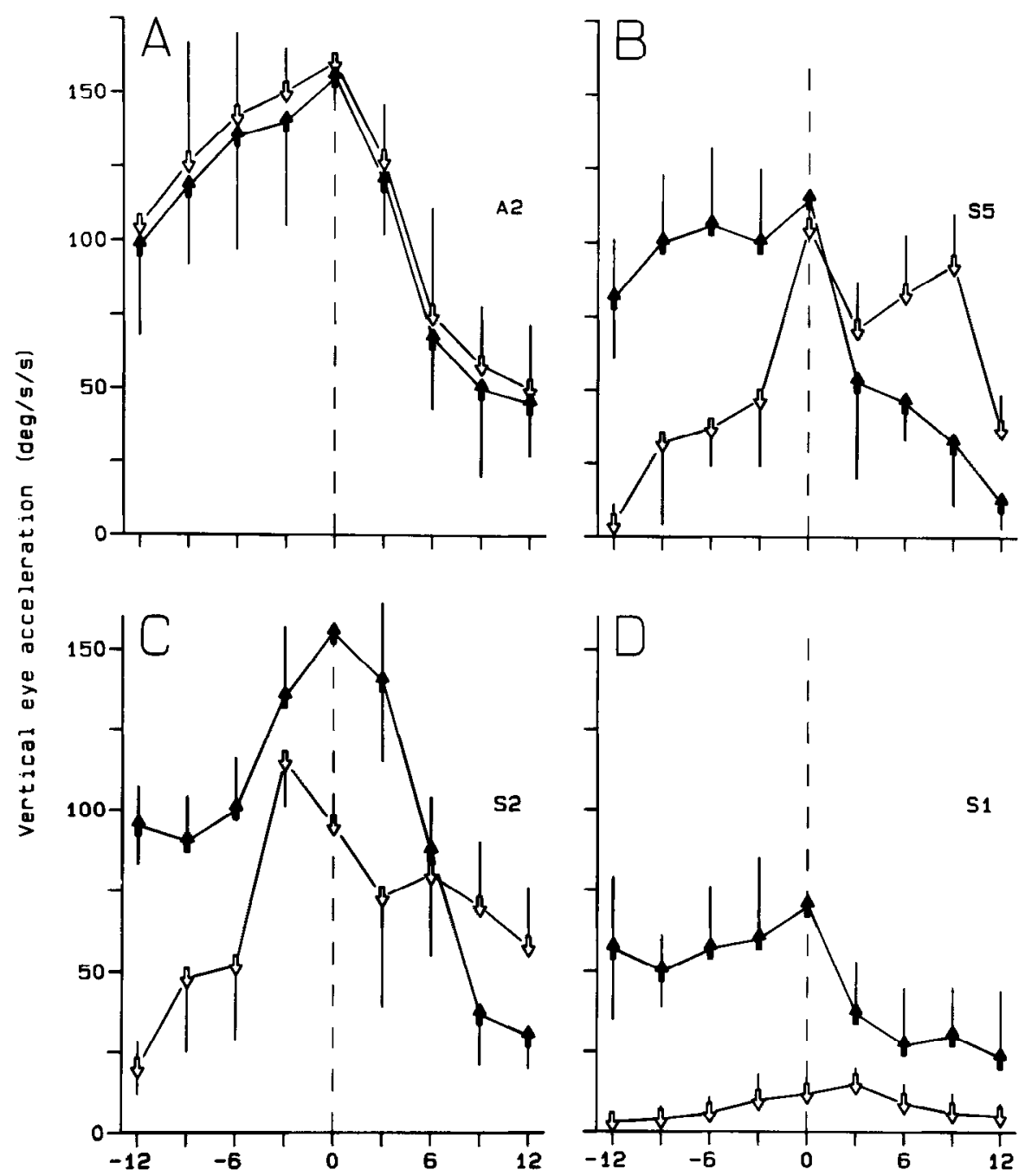

Initial target position (deg) 


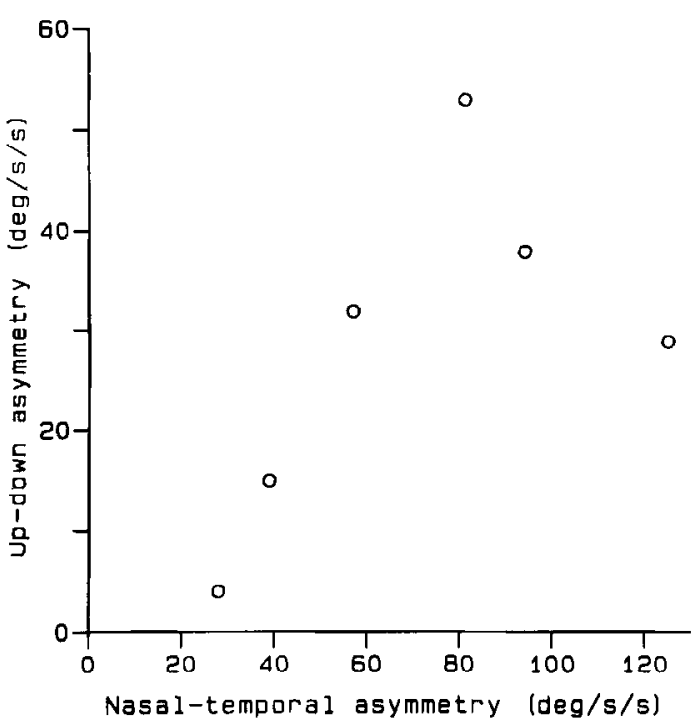

Figure 11. Comparison of up-down and nasal-temporal asymmetries in the initiation of pursuit. Each point represents the responses for viewing through 1 eye in 1 strabismic subject.

this ability to overcome the nystagmus.

Low-velocity targets provided an explanation for the failure of most subjects to overcome the nystagmus. Temporally directed target motion at low velocities evoked wrong-way pursuit, even in subjects who had only mild asymmetries for a target velocity of $30 \% \mathrm{sec}$. In the trial shown in Figure $9 \mathrm{~A}$, we presented leftward target motion at $1 \% \mathrm{sec}$ to the left eye of subject S5. At the time indicated by the arrow, the computer began to drive target position with a signal computed by adding eye position to the desired $1 \% \mathrm{sec}$ stimulus. As a result, the subject was unable to correct the small image velocity and the fixation nystagmus could not affect the velocity of the visual stimulus. In spite of the persistent leftward stimulus (temporally directed), the subject initiated rightward (nasally directed) pursuit and continued to accelerate smoothly to the right for the $400 \mathrm{msec}$ duration of the trial. Figure $9 B$ plots the mean eye acceleration for lowvelocity image motion as a function of initial target position for subject S5. Pursuit was consistently in the wrong direction (negative values of eye acceleration) when the target moved temporally at $1 \% \mathrm{sec}$, and it was in the correct direction but weak when the target moved temporally at $2.5 \% \mathrm{sec}$. For low-velocity stimuli, eye acceleration did not depend strongly on the initial target position or on the direction of target motion relative to the position of fixation.

In both subjects tested, the nasal-temporal pursuit asymmetry was larger for low- than for high-velocity target motion. The left eye of subject S5 had a pursuit asymmetry of $34 \% \mathrm{sec}^{2}$ for target motion at $30 \% \mathrm{sec}, 41 \% \mathrm{sec}^{2}$ for target motion at $2.5 \% \mathrm{sec}$, and $60 \% \mathrm{sec}^{2}$ for target motion at $1.0 \% \mathrm{sec}$ (Fig. 9B). In subject $\mathrm{S} 1$, the pursuit asymmetries were 124,130 , and $139 \% \mathrm{sec}^{2}$ at target velocities of $30,2.5$, and $1.0 \%$ sec, respectively.

\section{Initiation of vertical pursuit in normals}

The deficits in the vertical pursuit of strabismics can be appreciated only by comparison with the performance of normal humans, which is reviewed briefly here. Figure $10 \mathrm{~A}$ plots initial eye acceleration as a function of initial vertical target position for both upward and downward pursuit in 1 eye of a normal subject. Two general rules are apparent. First, the magnitudes of the upward and downward eye accelerations were essentially identical. Second, eye acceleration was always greatest when the

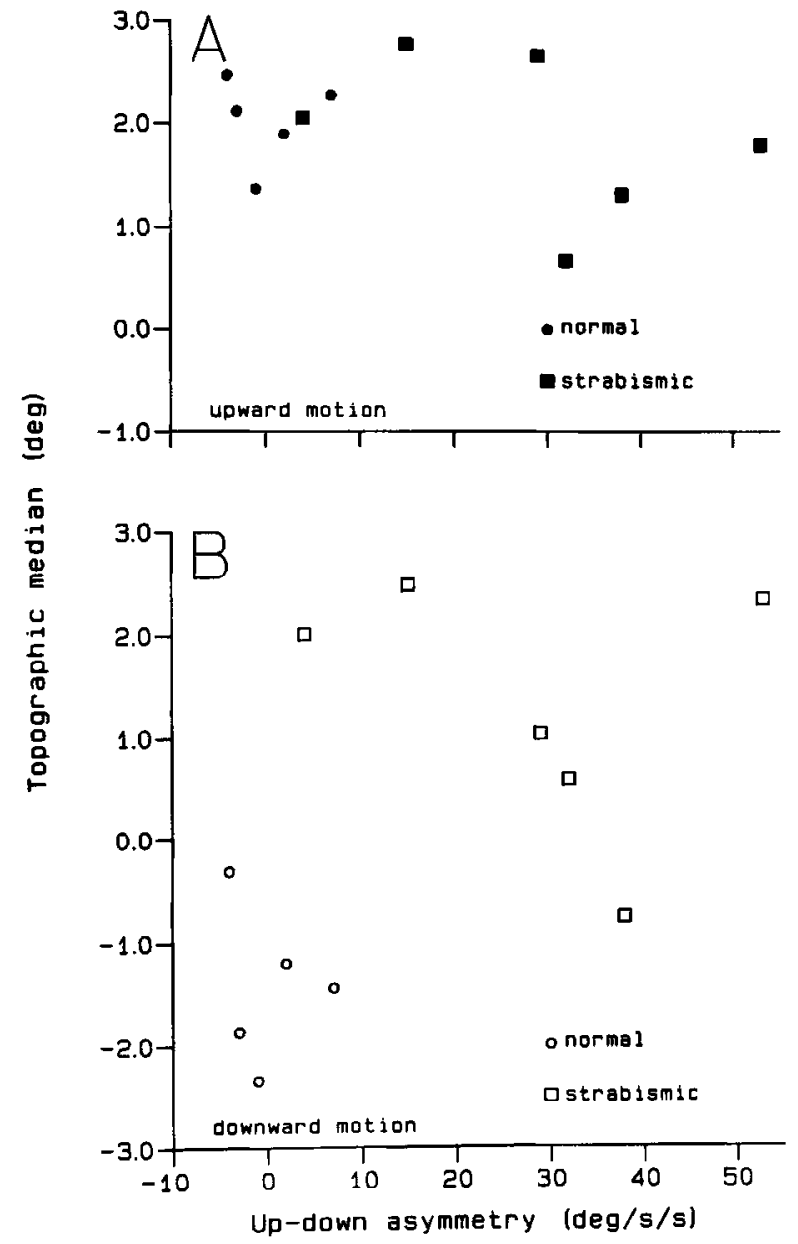

Figure 12. Abnormalities in the relative weighting of the visual field for the initiation of vertical pursuit in strabismics. Each point represents the responses for viewing through 1 eye in 1 normal (circles) or strabismic (squares) subject. Topographic median is an estimate of the center of the curve relating eye acceleration to the initial position of the tracking target. Positive values indicate that the eye acceleration was generally larger for target motion toward the position of fixation, and negative values indicate that eye acceleration favored target motion away from the position of fixation. Note that the abnormalities are small for upward target motion $(A)$ and large for downward target motion $(B)$.

target started in the lower visual field. Thus, upward pursuit was like normal horizontal pursuit in that eye acceleration was greatest when the target moved toward the position of fixation. Downward pursuit was different in that eye acceleration was greatest when the target moved away from the position of fixation. The responses shown in Figure $10 \mathrm{~A}$ are typical of 4 normal subjects whose data are reported in detail elsewhere (Tychsen and Lisberger, 1986).

\section{Abnormalities in the initiation of vertical pursuit}

In strabismic subjects, upward pursuit appeared to be normal. Downward pursuit showed abnormally low eye accelerations and had abnormalities in the relative weighting of different parts of the visual field. The peak upward eye acceleration was higher than the peak downward acceleration in 5 of the 6 eyes we studied in strabismic subjects. In Figure 10, $C$ and $D$, for example, the magnitude of the up-down asymmetry was $35^{\circ}$ and $53 \% \mathrm{sec}^{2}$. Figure 11 plots the magnitudes of the up-down asymmetry as a function of the nasal-temporal asymmetry. The asymmetries were correlated ( $R=0.67,6$ eyes), but the vertical 


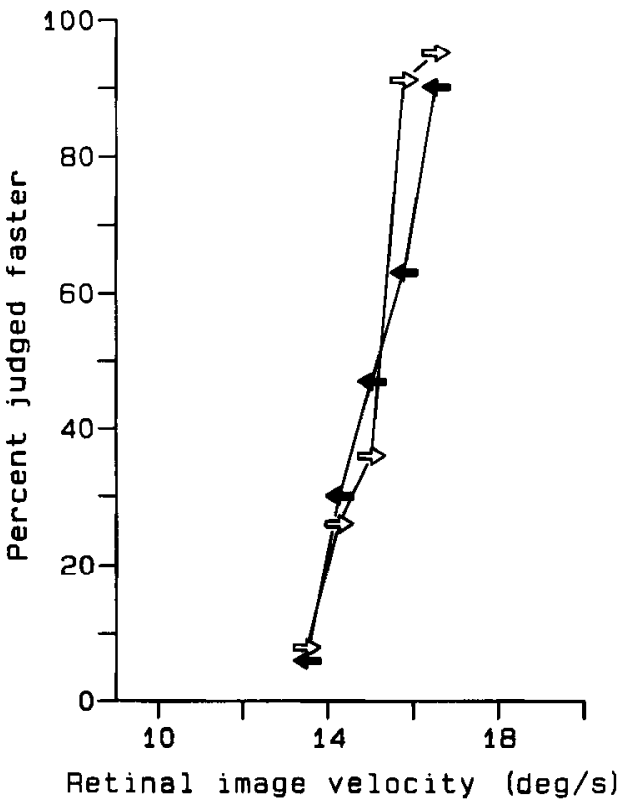

Figure 13. Velocity discrimination in a normal subject. Stimuli at 5 different speeds $(13.5,14.25,15.0,15.75,16.5 \%$ sec $)$ and 2 directions (right and left) were presented in random order. Each arrow shows the percentage of trials of each stimulus speed that were judged faster than the perceived mean for all trials seen up to that point. Viewing was monocular through the left eye.

asymmetry was usually less than half the magnitude of the horizontal asymmetry. There was also a correlation between the magnitude of the up-down asymmetry and the magnitude of the dissociated vertical deviation measured clinically (data not shown, $R=0.60,6$ eyes).

Inspection of Figure 10 reveals abnormalities in the weighting of different parts of the visual field for the initiation of downward pursuit. In Figure $10, B-D$, downward target motion produced larger eye accelerations when the target started in the upper visual field. Thus, strabismics showed greater eye accelerations for downward target motion toward the position of fixation. In contrast, normal subjects showed greater eye accelerations for downward target motion away from the position of fixation. We quantified the topography for vertical pursuit by again computing the topographic median for each curve relating eye acceleration to initial target position. For upward pursuit (Fig. $12 \mathrm{~A}$ ), the topographic median was similar in strabismics (squares) and normal subjects (circles). For downward pursuit (Fig. 12B), 5 of the 6 eyes we studied in strabismic subjects (squares) had positive values of topographic median, signifying that pursuit was initiated more vigorously for target motion toward the position of fixation. In contrast, all 5 eyes we studied in normal subjects (circles) had negative values of topographic median for downward pursuit, indicating a preference for target motion away from the position of fixation.

\section{Latency of pursuit initiation}

The mean latencies for the initiation of horizontal pursuit ranged from 102 to $125 \mathrm{msec}$ in the 7 strabismic subjects. All subjects had normal latencies for nasally directed target motion at $30 \%$ sec. Subjects S1, S3, and S6, for example, had mean latencies of $117 \pm 16,110 \pm 11$, and $110 \pm 10 \mathrm{msec}$, respectively. In subjects S3-S7, the latencies for temporally directed target motion were also normal. In subjects $\mathbf{S} 1$ and $\mathbf{S} 2$, who had the most severe pursuit asymmetries, the latencies for temporally directed target motion were an average of 11 and $21 \mathrm{msec}$ longer than those for nasally directed target motion. The mean latencies for the initiation of vertical pursuit ranged from 95 to $126 \mathrm{msec}$. There were no consistent differences for upward versus downward target motion, or upper versus lower visual field.

Nasal-temporal asymmetries in the psychophysical judgment of velocity

Two normal and 2 strabismic subjects viewed a stimulus that moved horizontally across a screen at 1 of 5 speeds. The speed and direction of stimulus motion were randomized. After each trial, the subject judged whether the speed of the stimulus he had just seen was faster or slower than a subjective mean based on all the stimuli seen up to that point.

Figure 13 plots the judgments of one normal subject for viewing through the left eye. Each arrow shows the percentage of trials that were judged to be faster than the mean for each speed and each direction of stimulus motion. The judgments were the same for left- and rightward stimulus motion, and the picture presented agrees well with the actual speeds of the stimuli. The stimulus that moved at the actual mean speed of $15 \%$ sec was judged to be faster than the mean in about $50 \%$ of the trials. Stimulus motion at $13.5 \% \mathrm{sec}$ was almost always judged to be slower than the mean, and stimulus motion at $16.5 \% \mathrm{sec}$ was almost always judged to be faster.

Figure $14, A$ and $B$, plots the judgments of the 2 strabismic subjects ( $\mathrm{S} 1$ and $\mathrm{S} 2$ ) who had the most severe asymmetries of horizontal pursuit. Each subject viewed with the left eye. Considered separately, the data for each direction of stimulus motion present a consistent picture. Slower stimuli were judged to be slower than the mean, and there was a smooth increase in the percentage judged faster as stimulus speed increased. Statistical analysis (McKee and Welch, 1985) revealed that the ability to discriminate differences in velocity was normal when each direction of motion was considered separately. The "velocity discrimination threshold," defined as the percentage difference in the speed of the stimulus that could be recognized accurately $50 \%$ of the time, was $10 \%$ for temporally directed stimuli and $6 \%$ for nasally directed stimuli. Normal subjects have velocity discrimination thresholds ranging from 5 to $9 \%$ (McKee and Welch, 1985).

Comparing the data for left- and rightward stimulus motion shows that both strabismic subjects judged nasally directed stimuli to be moving faster than the temporally directed stimuli. For example, the dots near the curves in Figure $14 A$ mark responses to stimuli that moved across the CRT at $12.75 \% \mathrm{sec}$. Because of the small nasally directed drift of the subject's fixation nystagmus, rightward or nasally directed stimulus motion at $12.75 \%$ sec (open arrow) had a retinal image velocity of $10.85 \% \mathrm{sec}$; temporally directed motion at $12.75 \%$ sec (filled arrow) had an image velocity of $14.65 \%$ sec. The subject judged the nasally directed stimuli to be faster than the subjective mean in $87 \%$ of the trials and the temporally directed stimuli to be faster in only $7 \%$ of the trials. Thus, despite the fact that the nasally directed stimuli caused image motion that was $3.8 \% \mathrm{sec}$ slower, they were judged to be moving faster. The consistency of this finding can be seen by considering all the points in Figure 14, $A$ and $B$. In the range of image speeds where the curves overlapped, nasally directed stimulus motion was always judged to be faster than temporally directed motion. When the subjects viewed with the other eye (not shown), the perceptual asymmetry reversed in terms of left and right, so that nasally directed motion was still seen as faster.

As shown in Figure 14, $A$ and $B$, nasally directed stimulus motion was almost always judged to be faster than the mean. As a result, the curves for nasally directed stimulus motion had shapes that were different from normal and appeared to emphasize the upper half of the normal curves. We were concerned that this might introduce small errors in our quantitative estimates of the magnitude of the nasal-temporal perceptual asym- 

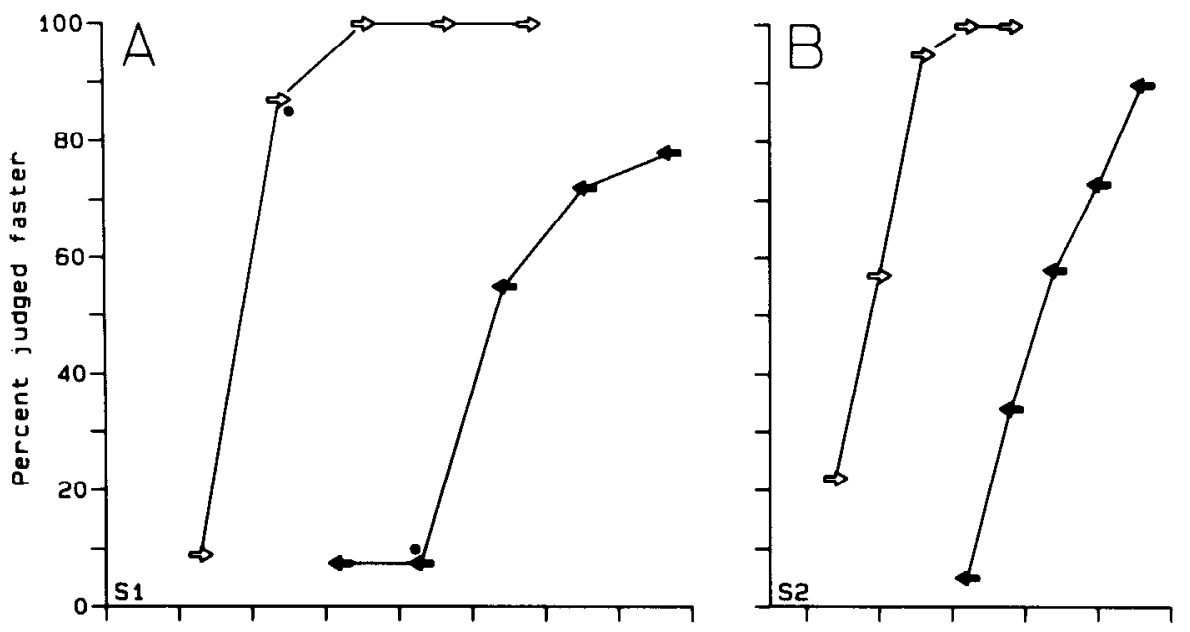

Figure 14. Nasal-temporal asymmetries in the judgment of stimulus velocity in strabismic subjects. Each panel shows the results of one experiment in which leftward and rightward stimuli at 5 speeds were inter-

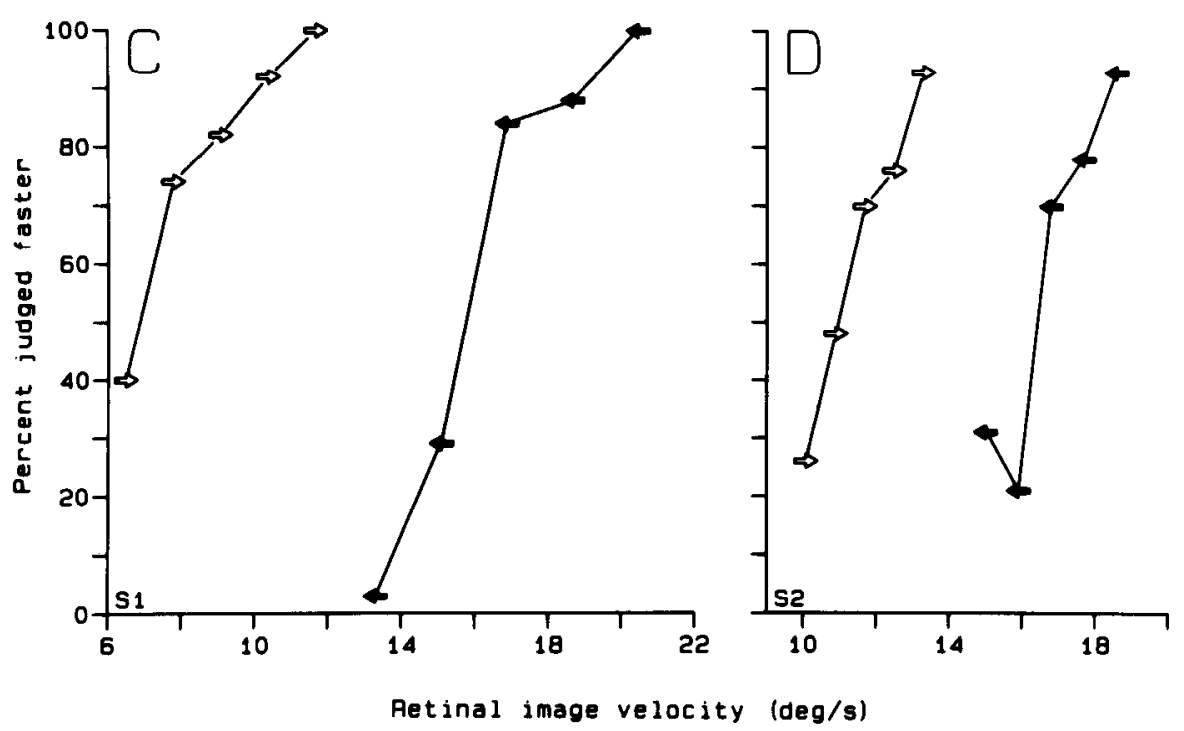
spersed randomly. Viewing was monocular through the left eye, so that open arrows represent nasally directed (rightward) stimulus motion. Each arrow shows the percentage of presentations at each speed and direction that was judged to be faster than the subjective mean. In $A$ and $B$, the nasally and temporally directed stimuli were drawn randomly from the same set of 5 velocities with a mean of $15 \%$ sec. In $C$, the mean nasally directed stimulus velocity was $11.5 \% \mathrm{sec}$, and the mean temporally directed stimulus velocity was $15 \%$ sec. In $D$, the mean nasally directed stimulus velocity was $13.5 \% \mathrm{sec}$, and the mean temporally directed stimulus velocity was $15 \%$ sec. In $A$, the 2 arrows indicated by dots show the judgments for nasally and temporally directed stimulus motion at the same speed $(12.75 \%$ sec) across the oscilloscope.

metry. To reduce the number of nasally directed stimuli that were judged to be faster than the mean, we lowered the velocities of only the nasally directed stimuli so that the middle of the 5 values was $11 \%$ sec in subject S1 (Fig. $14 C$ ) and $13.5 \%$ sec in subject S2 (Fig. 14D). The resulting curves for nasally directed stimulus motion now had the same shape as the curves for temporally directed motion, but they were still shifted to the left. This allowed us to do the following quantitative analysis.

For each direction of stimulus motion, we fitted a sigmoid curve to the data using least-square procedures. The "perceived mean speed" was defined as that speed for which the curve predicted that $50 \%$ of the presentations would be judged as faster than the mean. The nasal-temporal perceptual asymmetry was then estimated as the perceived mean for temporally directed motion minus that for nasally directed motion. In the 4 eyes of the 2 strabismic subjects we studied, the perceptual asymmetries were $9.0,5.2,1.6$, and $1.3 \%$ sec. For the same 4 eyes, the pursuit asymmetries were $125,94,82$, and $57 \% / \mathrm{sec}^{2}$, respectively. In both subjects the perceptual asymmetries were largest in the left eye and relatively smaller in the right eye (the right eye was the nonpreferred eye for normal viewing). In contrast, the normal subjects had perceptual asymmetries of $0.86 \% \mathrm{sec}$ or less. The asymmetry favored temporally directed motion in one normal subject and nasally directed motion in the other.

\section{Discussion}

We found deficits in visual motion processing in adult humans who had strabismus with onset in infancy. The deficits were apparent in the pursuit eye movements evoked by moving targets and in the perception of target motion independent of eye movement. Our data imply that the deficits are due to a maldevelopment of motion processing in the visual cortex. Here, we will consider 2 possible cause-and-effect relationships that may underlie our observations. Correct ocular alignment in the critical period may be necessary for the development of a normal balance between temporally and nasally directed motion processing, or, alternatively, a congenital emphasis of nasally directed motion processing may cause esotropic strabismus.

\section{Pursuit initiation as a measure of visual motion processing}

We took advantage of methods that were developed on normal primates (Lisberger and Westbrook, 1985; Tychsen and Lisberger, 1986) to use pursuit eye movements as a tool for studying the properties of visual motion processing in strabismics. By measuring the first $100 \mathrm{msec}$ of pursuit, we restricted our attention to that portion of the eye movement that precedes visual feedback. This allowed us to uncover "wrong-way" pursuit, which was not evident after there had been time for corrective 
feedback. Analysis of the initiation of pursuit was also necessary to reveal abnormalities in the relative weighting of different parts of the visual field and for verifying that the site of the deficit was in the afferent, rather than the efferent, limb of the pursuit system.

It would be difficult to explain the deficits we found as a motor weakness. First, the deficient direction of horizontal pursuit could be rendered normal instantaneously by changing the eye used for viewing. Second, humans with infantile strabismus have normal saccadic velocities (Hain et al., 1985) and normal smooth eye movements evoked by head rotation in darkness (Tychsen et al., 1985). The same facts argue that the pursuit deficits cannot have resulted from the muscle surgery performed to align the eyes. Each eye was able to undergo rapid, temporally directed eye accelerations during the vestibulo-ocular reflex (VOR) and saccades, and even during pursuit if the stimulus was presented to the other eye. Finally, it is not possible to attribute the deficits in pursuit to algebraic summation of the fixation nystagmus and a normal pursuit response. The velocity of the nystagmus was much too small to account for the pursuit deficits and merely provided a nonzero baseline against which we measured deficits in eye acceleration.

\section{The visual cortex as the site of maldevelopment in} motion processing

We believe that the deficits we have found result from a maldevelopment of motion processing in the visual cortex. Several lines of evidence argue that the cortical motion processing pathways provide the visual inputs for pursuit. Cortically blind humans are unable to pursue (Brindley et al., 1969; Velzeboer, 1952), and damage to the parieto-occipital areas of the visual cortex causes deficits both in pursuit (Baloh et al., 1980; Leigh and Tusa, 1985; Leigh and Zee, 1982; Sharpe et al., 1979; Troost et al., 1972) and in the detection of visual motion (Damasio, 1985; Zihl et al., 1983). In monkeys, lesions in either the primary visual cortex (Goldberg et al., 1982; Zee et al., 1985) or the middle temporal visual area (MT) (Newsome et al., 1985) cause deficits in the initiation of pursuit. In the latter study, the use of step-ramp target motion showed that the deficit was in the afferent limb of the pursuit system, since pursuit was poor only when the moving target started in the part of the visual field whose representation in area MT had bcen destroyed.

It would be possible to argue that our subjects have 2 deficits, 1 in the cerebral pathways responsible for velocity perception and 1 in the cerebral pathways that subserve pursuit. However, the correspondence between the perceptual and pursuit asymmetries argues that both result from a common deficit. We suggest that the deficit is in pathways that process visual motion and that these pathways provide signals used both for the perception of motion and for the initiation of smooth pursuit eye movements.

\section{Development of visual motion processing}

Our findings imply that the pathways mediating motion processing are immature at birth and that they develop normally only if the animal experiences binocular correspondence throughout early life. Further, it appears that binocularity and motion processing normally develop in parallel and that they have similar critical periods. Healthy human and monkey infants lack signs of normal binocular function (for a review see Boothe et al., 1985) and have directional asymmetries in visual tracking similar to those seen in our subjects. With monocular viewing, small-field optokinetic stimuli elicit deficient nystagmus when the direction of stimulus motion is temporal or downward (Atkinson, 1979; Atkinson and Braddick, 1981; Hainline et al., 1984; Naegele and Held, 1982). These asymmetries disappear by about 6 months of age if signs of normal binocularity appear (Atkinson, 1979; Naegele and Held, 1982).
The critical factor in producing deficits in motion processing appears to be a loss of binocularity in infancy rather than visual deprivation. Thus, our subjects, like the majority of humans with infantile strabismus (Von Noorden, 1980), had no amblyopia or other evidence of visual deprivation. Most previous work on the development of visual tracking has been done on visually deprived animals (Harris and Cynader, 1981; Van Hofvan Duin, 1976; Vital-Durand et al., 1974) or humans (Lewis et al., 1985; Schor and Levi, 1980). Although these studies used large "optokinetic" rather than small "pursuit" stimuli, they found deficits analogous to those reported here. We presume that the deficits result from the absence of normal binocular experience rather than from the deprivation itself.

Current knowledge offers no specific models that explain how the development of motion processing might depend on binocular correspondence during the critical period. However, strabismus in the critical period causes a loss of binocularity in the responses of cells in the primary visual cortex (Crawford and Von Noorden, 1979; Hubel and Wiesel, 1965; Van Sluyters and Levitt, 1980), and recent work has shown that synchronous activity in the inputs from the 2 eyes is necessary for the development of cortical binocularity (Fawcett and O'Leary, 1985; Stryker, 1986). In general terms, it seems plausible that one class of maldevelopment (binocularity) in the visual cortex might cause another (motion processing). As an alternative, a maldevelopment in the primary visual area might lead to maldevelopments in areas such as MT that receive abundant inputs from the striate cortex (Ungerleider and Mishkin, 1979).

\section{Relationship between visual motion processing and the} clinical signs of infantile strabismus

In the preceding sections, we have concentrated on the possibility that strabismus is the primary deficit in our subjects and that the loss of normal ocular alignment in the critical period causes a maldevelopment of cortical motion processing. The cause of the clinical ocular motor symptoms of strabismus is unknown, however, and it is possible that the maldevelopment of cortical motion processing is the primary deficit. Our results are compatible with this idea, since the deficits we have found in motion processing would be appropriate to cause the fixation nystagmus, dissociated vertical deviation, and even the esotropic strabismus.

Several of our observations suggest that the fixation nystagmus has a visual basis and may be secondary to the deficits in motion processing. First, the nystagmus was accentuated by vision and its direction was determined by the viewing eye. Second, the velocity of the nystagmus was correlated with the magnitude of the nasal-temporal pursuit asymmetry. Third, wrong-way pursuit at low velocities suggests that these subjects experience an unstable visual situation during monocular viewing, in the form of visual motion information calling for a nasally directed drift. In normal adult monkeys, persistent viewing of a visual scene moving in one direction causes an ocular motor adaptation: The animal acquires a nystagmus that persists for hours in total darkness (Miles, 1976). We suggest that the fixation nystagmus in strabismics represents a similar ocular motor adaptation. Even when the object of fixation is stationary, visual inputs report nasally directed motion and therefore command nasally directed pursuit. Ultimately the motor pathways adapt and the nystagmus persists, even in darkness.

It is also possible to see how the imbalance of vertical motion processing could cause the dissociated vertical deviation (DVD). The up-down visual asymmetry in a strabismic eye would provide a constant drive for upward drift. The relatively weak correlation between the magnitude of the up-down visual bias and the magnitude of the DVD appears to argue against a strict cause and effect relationship. However, the DVD is difficult to measure rigorously and varies over a small range among sub- 
jects, so the weak correlation may represent methodological problems.

The question of cause and effect is especially difficult to unravel for the esotropic strabismus itself. Although 3-4\% of humans develop strabismus early in life (NIH, 1983), the cause of infantile strabismus is not known, and existing theories are vague (Dale, 1983; Parks, 1984a; for a review, see Von Noorden, 1980). The eye muscles and lower motor centers appear to be normal in infantile esotropia (Hain et al., 1985; Tychsen et al., 1985). One clue may lie in the fact that in the first months of life, normal infants have an asymmetry in the optokinetic response that strongly favors nasally directed motion in each eye (Atkinson, 1979; Naegele and Held, 1982). Thus, the immature visual motion system apparently provides a tonic drive that would promote crossed eyes.

We suggest that the nasally directed drive is normally opposed by a fragile mechanism designed to keep the 2 visual axes aligned. Any one of a variety of congenital or neonatal insults (including a congenital maldevelopment of temporally directed motion processing) could weaken this mechanism, allowing the normal nasally directed bias of the visual motion system to dominate. The nasally directed visual bias would gradually drive both eyes nasally, creating an esotropic strabismus. A vicious cycle might then ensue. The esotropia would disrupt binocular correspondence and thereby interfere with the maturation of a temporally directed motion system. This would deprive the brain of any means to oppose the esotropic drive. Our idea is obviously highly speculative, but it has an attractive feature. The normal nasally directed bias of the infant motion system favors the development of esotropia and could explain the fact that esotropia is at least 30 times more common than exotropia in cases of strabismus with onset in infancy (Parks, 1984b).

\section{References}

Atkinson, J. (1979) Development of optokinetic nystagmus in the human infant and monkey infant. In Developmental Neurobiology of Vision, R. D. Freeman, ed., pp. 277-287, Plenum, New York.

Atkinson, J., and O. Braddick (1981) Development of optokinetic nystagmus in infants: An indicator of cortical binocularity? In Eye Movements: Cognition and Visual Perception, D. F. Fisher, R. A. Monty, and J. W. Senders, eds., pp. 53-64, Erlbaum, Hillsdale, NJ.

Baloh, R. W., R. D. Yee, and V. Honrubia (1980) Optokinetic nystagmus and parietal lobe lesions. Ann. Neurol. 7: 269-276.

Boothe, R. G., V. Dobson, and D. Y. Teller (1985) Postnatal development of vision in human and nonhuman primates. Annu. Rev. Neurosci. 8: 495-545.

Brindley, G. S., P. C. Gautier-Smith, and W. Lewin (1969) Cortical blindness and the functions of the non-geniculate fibers of the optic tracts. J. Neurol. Neurosurg. Psychiatr. 32: 259.

Collewijn, H., F. Van Der Mark, and T. C. Jansen (1975) Precise recording of human eye movements. Vision Res. 15: 447-450.

Crawford, M. L. J., and G. K. Von Noorden (1979) The effects of short-term experimental strabismus on the visual system in Macaca mulatta. Invest. Ophthalmol. Vis. Sci. 18: 496-505.

Dale, R. T. (1982) Fundamentals of Ocular Motility and Strabismus, p. 201, Grune \& Stratton, New York.

Damasio, A. R. (1985) Disorders of complex visual processing: Agnosia, achromatopsia, Balint's syndrome, and related difficulties of orientation and construction. In Principles of Behavioral Neurology, M.-M. Mesulam, ed., p. 276, Davis, Philadelphia, PA.

Fawcett, J. W., and D. D. M. O'Leary (1985) The role of electrical activity in the formation of topographic maps in the nervous system. Trends Neurosci. 8: 201-206.

Fuchs, A. F. (1967) Saccadic and smooth pursuit eye movements in the monkey. J. Physiol. (Lond.) 191: 609-631.

Goldberg, M. E., C. J. Bruce, L. Ungerleider, and M. Mishkin (1982) Role of the striate cortex in generation of smooth pursuit eye movements. Ann. Neurol. 12: 113.

Hain, T. C., S. E. Kelman, and D. S. Zee (1985) Pursuit and saccadic asymmetries in latent nystagmus. Soc. Neurosci. Abstr. 11:471.

Hainline, L., E. Lemerise, I. Abramov, and J. Turkel (1984) Orien- tational asymmetries in small-field optokinetic nystagmus in human infants. Behav. Brain Res. 13: 217-230.

Harris, L. R., and M. Cynader (1981) The eye movements of the darkreared cat. Exp. Brain Res. 44: 41-56.

Hubel, D. H., and T. N. Wiesel (1965) Binocular interaction in striate cortex of kittens reared with artificial squint. J. Neurophysiol. 28: 1041-1059.

Lang, J. (1984) Strabismus, p. 97, Slack, Thorofare, NJ.

Leigh, R. J., and R. J. Tusa (1985) Disturbance of smooth pursuit caused by infarction of occipitoparietal cortex. Ann. Neurol. 17:185187.

Leigh, R. J., and D. S. Zee (1983) The Neurology of Eye Movement, p. 77, Davis, Philadelphia, PA.

Lewis, T. L., D. Maurer, and H. P. Brent (in press) Optokinetic nystagmus in children treated for bilateral cataracts. In Eye Movements and Human Information Processing, R. Groner, G. W. McConkie, and C. Menz, eds., North-Holland, Amsterdam.

Lisberger, S. G., and L. E. Westbrook (1985) Properties of visual inputs that initiate horizontal smooth pursuit eye movements in monkeys. J. Neurosci. 5: 1662-1673.

Maunsell, J. H. R., and D. C. Van Essen (1983) Functional properties of neurons in middle temporal visual area of the macque monkey. II. Binocular interactions and sensitivity to binocular disparity. $J$. Neurophysiol. 49: 1148-1167.

McKee, S. P., and L. Welch (1985) Sequential recruitment in the discrimination of velocity. J. Opt. Soc. Am. A 2: 243-251.

Miles, F. A. (1976) Effects of a continuously moving environment on the rhesus monkey's ocular stability in the dark. Soc. Neurosci. Abstr. 2: 273.

Mohindra, I., J. Zwaan, R. Held, S. Brill, and R. Zwaan (1985) Development of acuity and stereopsis in infants with esotropia. Ophthalmol. 92: 691-697.

Movshon, J. A., and R. C. Van Sluyters (1981) Visual neural development. Ann. Rev. Psychol. 32: 477-522.

Naegele, J. R., and R. Held (1982) The postnatal development of monocular optokinetic nystagmus in infants. Vision Res. 22: 341346.

National Institutes of Health (1983) Report of the strabismus, amblyopia, and visual processing panel, Vol. 2, Pt. 5. In Vision Research: A National Plan 1983-1987, p. 1, U.S. Department of Health and Human Services, Public Health Service, NIH, Bethesda, MD (publication no. 83-2475).

Newsome, W. T., R. H. Wurtz, M. R. Dursteler, and A. Mikami (1985) Deficits in visual motion processing following ibotenic acid lesions of the middle temporal visual area of the macaque monkey. J. Neurosci. 5: $825-840$.

Parks, M. M. (1984a) Concomitant esodeviations. In Clinical Ophthalmology, Vol. 1, T. D. Duane and E. A. Jaeger, eds., p. 7, Harper \& Row, Philadelphia, PA.

Parks, M. M. (1984b) Concomitant exodeviations. In Clinical Ophthalmology, Vol. 1, T. D. Duane and E. A. Jaeger, eds., p. 3, Harper \& Row, Philadelphia, PA.

Rashbass, C. (1961) The relationship between saccadic and smooth tracking eye movements. J. Physiol. (Lond.) 159: 326-338.

Robinson, D. A. (1963) A method of measuring eye movement using a scleral search coil in a magnetic field. IEEE Trans. Bio-Med. Electron. 10: 137-145.

Schor, C. M., and D. M. Levi (1980) Disturbances of small-field horizontal and vertical optokinetic nystagmus in amblyopia. Invest. Ophthalmol. Vis. Sci. 19: 668-683.

Sharpe, J. A., A. W. Lo, and H. E. Rabinovitch (1979) Control of the saccadic and smooth pursuit systems after cerebral hemidecortication. Brain 102: 387-403.

Stryker, M. P. (1986) Evidence for a possible role of spontaneous electrical activity in the development of mammalian visual cortex. In Developmental Neuroscience, P. Kellaway, ed., Johns Hopkins U.P., Baltimore, MD.

Troost, B. T., R. B. Daroff, R. B. Weber, and L. F. Dell'Osso (1972) Hemispheric control of eye movements. II. Quantitative analysis of smooth pursuit in a hemispherectomy patient. Arch. Neurol. 27:449452.

Tychsen, L., and S. G. Lisberger (in press) Visual motion processing for the initiation of smooth pursuit eye movements in humans. $J$. Neurophysiol.

Tychsen, L., R. R. Hurtig, and W. E. Scott (1985) Pursuit is impaired 
but the vestibulo-ocular reflex is normal in infantile strabismus. Arch. Ophthalmol. 103: 536-539.

Ungerleider, L. G., and M. Mishkin (1979) The striate projection zone in the superior temporal sulcus of Macaca mulatta: Location and topographic organization. J. Comp. Neurol. 188: 347-366.

Van Essen, D. C., and J. H. R. Maunsell (1983) Hierarchical organization and functional streams in the visual cortex. Trends Neurosci. 6: $370-375$.

Van Hof-van Duin, J. (1976) Early and permanent effects of monocular deprivation on pattern discrimination and visuomotor behavior in cats. Brain Res. 111: 261-276.

Van Sluyters, R. C., and F. B. Levitt (1980) Experimental strabismus in the kitten. J. Neurophysiol. 43: 686-699.

Velzeboer, C. M. J. (1952) Bilateral cortical hemianopsia and optokinetic nystagmus. Ophthalmologica 123: 187.
Vital-Durand, F., P. T. S. Putkonen, and M. Jeannerod (1974) Motion detection and optokinetic responses in dark-reared kittens. Vision Res. 14: 141.

Von Noorden, G. K. (1980) Burian-Von Noorden's Binocular Vision and Ocular Motility: Theory and Management of Strabismus, pp. 150-165, 183, 271, 295, Mosby, St. Louis, MO.

Wiesel, T. N. (1982) Postnatal development of the visual cortex and the influence of environment. Nature 299: 583-591.

Zee, D. S., R. J. Tusa, P. H. Butler, S. J. Herdman, and G. Gucer (in press) The acute and chronic effects of bilateral occipital lobectomies on eye movements in monkey. In Adaptive Processes in Visual and Oculomotor Systems, E. Keller and D. S. Zee, eds., Pergamon, New York.

Zihl, J., D. Von Cramon, and N. Mai (1983) Selective disturbance of movement vision after bilateral brain damage. Brain 106: 313-340. 